IZA DP No. 5118

Assortative Mating and Female Labor Supply

Christian Bredemeier

Falko Juessen

August 2010

Forschungsinstitut zur Zukunft der Arbeit Institute for the Study of Labor 


\title{
Assortative Mating and Female Labor Supply
}

\author{
Christian Bredemeier \\ University of Dortmund (TU) \\ and Ruhr Graduate School in Economics \\ Falko Juessen \\ University of Dortmund (TU) \\ and IZA
}

\section{Discussion Paper No. 5118 \\ August 2010}

IZA

P.O. Box 7240

53072 Bonn

Germany

Phone: +49-228-3894-0

Fax: +49-228-3894-180

E-mail: iza@iza.org

Any opinions expressed here are those of the author(s) and not those of IZA. Research published in this series may include views on policy, but the institute itself takes no institutional policy positions.

The Institute for the Study of Labor (IZA) in Bonn is a local and virtual international research center and a place of communication between science, politics and business. IZA is an independent nonprofit organization supported by Deutsche Post Foundation. The center is associated with the University of Bonn and offers a stimulating research environment through its international network, workshops and conferences, data service, project support, research visits and doctoral program. IZA engages in (i) original and internationally competitive research in all fields of labor economics, (ii) development of policy concepts, and (iii) dissemination of research results and concepts to the interested public.

IZA Discussion Papers often represent preliminary work and are circulated to encourage discussion. Citation of such a paper should account for its provisional character. A revised version may be available directly from the author. 
IZA Discussion Paper No. 5118

August 2010

\section{ABSTRACT}

\section{Assortative Mating and Female Labor Supply}

This paper investigates the pattern of wives' hours disaggregated by the husband's wage decile. In the US, this pattern has changed from downward-sloping to hump-shaped. We show that this development can be explained within a standard household model of labor supply when taking into account trends in assortative mating. We develop a model in which assortative mating determines the wage ratios within individual couples and thus the efficient time allocation of spouses. The economy-wide pattern of wives' hours by the husband's wage is downward-sloping for low degrees, hump-shaped for medium degrees, and upward-sloping for high degrees of assortative mating. A quantitative analysis of our model suggests that changes in the gender wage gap are responsible for the overall increase in hours worked by wives. By contrast, the fact that wives married to high-wage men experienced the most pronounced increase is a result of trends in assortative mating.

JEL Classification: E24, J22, J16, D13

Keywords: female labor supply, assortative mating, gender wage gap

Corresponding author:

Falko Juessen

Technische Universität Dortmund

Wirtschafts- und Sozialwissenschaftliche Fakultät

Volkswirtschaftslehre (Makroökonomie)

D-44221 Dortmund

Germany

E-mail: falko.juessen@tu-dortmund.de 


\section{Introduction}

Hours worked of married women in the US increased substantially over the second half of the last century. The most prominent explanation for rising hours of wives is the closure of the gender wage gap, i.e. the catching-up of female wages relative to men's wages, see e.g. Galor and Weil (1996), Jones, Manuelli, and McGrattan (2003), Knowles (2007), and Attanasio, Low, and Sánchez-Marcos (2008). According to household models of labor supply (see Chiappori 1988; Apps and Rees 1997; Blundell, Chiappori, Magnac, and Meghir 2007), labor supply of a wife depends on both the wife's and the husband's characteristics. Many empirical studies estimate cross-wage elasticities of female labor supply and find a significant influence of husbands' wages on working hours of wives, see Blau and Kahn (1997), Blundell, Duncan, and Meghir (1998), Devereux (2004, 2007), and Morissette and Hou (2008).

In this paper, we investigate wives' hours disaggregated by the husband's wage decile. Juhn and Murphy (1997) have performed an empirical stratification of wives' hours by the husband's wage and document a clearly downward sloping relation for the late 1960s and for the 1970s. Juhn and Murphy (1997) also find that the increase in hours worked of wives over time has been strongly non-uniform among all groups of married women, with wives of middle- and high-wage men experiencing more pronounced increases in hours than wives married to low-wage husbands. As a consequence, the pattern of wives' hours by the husband's wage has changed from negative to hump-shaped. Similar findings are reported by Morissette and Hou (2008) and Schwartz (2010).

Thus, a view on disaggregated labor supply of married women reveals the following two stylized observations. First, the pattern of wives' hours by the husband's wage has changed from downward-sloping to hump-shaped. Second, women married to men with high wages have experienced the strongest increases in hours worked. This paper aims at explaining these two empirical observations.

We highlight the role of assortative mating for understanding the economy-wide pattern of wives' hours by the husband's wage decile. Assortative mating is the tendency of spouses with similar characteristics to marry each other. The relevance of assortative mating for spouses' labor-supply decisions has been emphasized by Pencavel (1998) and Devereux (2004) who stress that, when seeking to interpret the observed 
relation between husbands' characteristics and wives' work decision, one needs to take into account that husbands' and wives' characteristics are usually correlated.

In this paper, we demonstrate that a standard household model of labor supply (Chiappori 1988; Apps and Rees 1997; Blundell, Chiappori, Magnac, and Meghir 2007) can generate the observed economy-wide pattern of wives' hours by the husband's wage when one takes into account trends in assortative mating. We measure assortative mating in terms of wage potentials. For a low degree of assortative mating (i.e. mating is almost random), our model generates a downward-sloping pattern of wives' hours by the husband's wage. By contrast, this pattern is hump-shaped for more pronounced assortative mating. Thus, when the degree of assortative mating increases, this induces a non-uniform change in wives' hours worked by the husband's wage decile. Specifically, the increase in hours is most pronounced for women married to top-wage husbands.

The economy-wide pattern of wives' hours by the husband's wage can change due to two reasons: first, changes in the relation between the husband's wage and the wife's labor supply at the household level and, second, compositional effects which may arise because the fractions of spouses marrying in different ways changes. In our model, the relation at the micro level is stable but the aggregated pattern of wives' hours by the husband's wage depends on assortative mating.

Specifically, patterns in hours in our model depend on the joint distribution of wages in marriages, i.e. on the marginal distributions of gender-specific wages and the association between spouses' wages. Couples face a specialization decision with respect to market work and home production. Within a couple, the efficient time allocation depends on the wage ratio of the two spouses. Only when the wife's relative wage is high enough, the couple opts for labor market participation of both spouses. Conditional on participation, hours of the wife are an increasing function of her relative wage.

To illustrate the effects of assortative mating, consider first the extreme cases of perfect sorting and random mating. Under random mating, every husband is on average married to the wife earning the average female wage independent of his own wage. Therefore, the relative wages are on average lowest for wives married to top-wage husbands. As a consequence, these wives work the fewest hours and the pattern of wives' 
hours by the husband's wage is downward-sloping.

Under perfect sorting, there exist only marriages where both wife and husband are from the same quantile in the respective gender-specific wage distribution. Husband's and wife's wages are thus perfectly correlated though not necessarily identical. The pattern of wives' hours by the husband's wage will then also depend on the marginal distributions of gender-specific wages. For example, with identical gender-specific distributions and perfect sorting, the wage ratio is one in each couple. Consequently, all wives work the same and the pattern of wives' hours by the husband's wage is flat. By contrast, when there is a gender wage gap, the wife's relative wage can also be increasing in the husband's wage. The reason is that an absolute wage gap is less important in relative terms when absolute wages of the two spouses are high. In couples where the husband's wage is relatively low, the wage gap translates into pronounced relative wage differences between husband and wife. Since the wife's relative wage can be increasing in the husband's wage, also hours worked of the wife can be increasing in the husband's wage.

We can imagine intermediate sorting as a combination of the two extreme cases, a fraction of the population marrying randomly and a fraction marrying in a perfectly assortative way. The resulting pattern of wives' hours worked by the husband's wage decile is therefore a weighted average of the patterns in the two extreme cases.

For the fraction of the population marrying in a random way, the pattern of wives' hours by the husband's wage decile is downward sloping independent of the wage gap. By contrast, for the fraction of the population marrying in a perfectly assortative way, the pattern can be upward sloping with the steepness depending on relative wage differences between husband and wife. The pattern is strongly increasing where wages are low and relative wage differences are thus pronounced. The pattern is almost flat for couples with high absolute wages and thus low relative wage differences. The resulting economy-wide pattern of wives' hours by the husband's wage decile can therefore be hump-shaped depending on the relative sizes of the two population groups marrying randomly and perfectly assortatively, respectively. Trends in assortative mating thus alter the pattern of wives' hours by the husband's wage decile observed in the aggregate and consequently lead to a non-uniform change in hours worked by wives.

From previous studies, there is much evidence that assortative mat- 
ing in the US has indeed become stronger over time. Most studies have investigated assortative mating in terms of educational attainment and found that husband and wife have become more similar with respect to education over time, see Mare (1991), Kalmijn (1991a), Kalmijn (1991b), Qian and Preston (1993), Pencavel (1998), Qian (1998), Schwartz and Mare (2005), Sánchez-Marcos (2008), and Schwartz (2010). Cancian and Reed (1998) and Schwartz (2010) report increased assortative mating by income. Sweeney and Cancian (2004) provide evidence for an increasing correlation between wife's wage and husband's income. Herrnstein and Murray (1994) report increased sorting by academic ability in higher education and by intelligence. In this paper, we use data from the Current Population Survey (CPS) to measure trends in assortative mating in terms of wage potentials. We find strong evidence that assortative mating in terms of wages has increased substantially over time.

To investigate whether empirically observed trends in the marginal and joint distributions of wages imply patterns in hours that are consistent with the empirical developments, we feed the observed distributions of wages into our model. We measure the association between spouses' wages in terms of the number of marriages that exist between different deciles of the gender-specific marginal wage distributions. By measuring assortative mating in terms of wage deciles, we can disentangle changes in the marginal distributions of husbands' and wives' wages from changes in the association between spousal wages.

The data shows a closure of the gender wage gap and a clear trend towards stronger assortative mating in terms of wages. Our empirical investigation suggests that trends in the marginal wage distributions are responsible for the overall increase in hours worked by wives. By contrast, the fact that wives married to high-wage men experienced the most pronounced increase is primarily a result of trends in assortative mating rather than being due to changes in the marginal wage distributions.

The remainder of this paper is organized as follows. In Section 2, we present the empirical facts on married women's labor supply we aim to explain as well as empirical evidence for increasing marital sorting in terms of wages. Section 3 presents the theoretical model that uses as an input the association between spousal wages to predict optimal labor supply decisions. Section 4 provides an quantitative analysis where we use the empirically observed joint distributions of wages. Section 5 concludes and an appendix follows. 


\section{Wives' hours by the husband's wage decile and trends in assortative mating}

In this section, we present the empirical facts we aim to explain. The key observation we address is that the increase in married women's labor supply has not been uniform among all wives. We also illustrate in this section that assortative mating in terms of wages has increased substantially over time.

The non-uniform increase in women's hours has been documented by e.g. Juhn and Murphy (1997) and Schwartz (2010) and is illustrated in Figure 1. The data are from the Current Population Survey (CPS) in the US. The left panel shows average weekly hours worked of wives married to men in the 10 deciles of the male wage distribution. The figure compares two periods of time, 1975-1979 (darkly shaded bars) and 2000-2006 (white bars). We form subperiods of more than one year to control for business cycle effects. The sample consists of matched husband-wife pairs of ages 30-50. Details on the data employed can be found in Appendix A.

During the 1970s, there has been a clear downward-sloping pattern of wives' hours by the husband's position in the wage distribution. Women married to high-wage men tended to work less hours. In the more recent period, this relationship has changed with wives of men in the middle of the wage distribution working the most. Thus, the pattern of wives' hours by the husband's wage has changed from downward-sloping to hump-shaped. ${ }^{1}$

The right panel in Figure 1 shows the change (between the two periods) in weekly hours worked by married women disaggregated by the husband's wage decile. One can see that hours worked of wives increased substantially among all groups of married women over time. However, the increase has been strongly non-uniform across husband's wage deciles. Increases in hours have been largest for wives of middleand high-wage men. By contrast, the increase in labor supply was relatively weak among wives of men in the low wage deciles.

The empirical facts we aim to explain can thus be summarized as follows:

\footnotetext{
${ }^{1} \mathrm{~A}$ similar picture emerges when one considers changes in participation rates instead of changes in hours worked (detailed results are available upon request).
} 
Figure 1: Wives' weekly hours by the husband's wage decile.
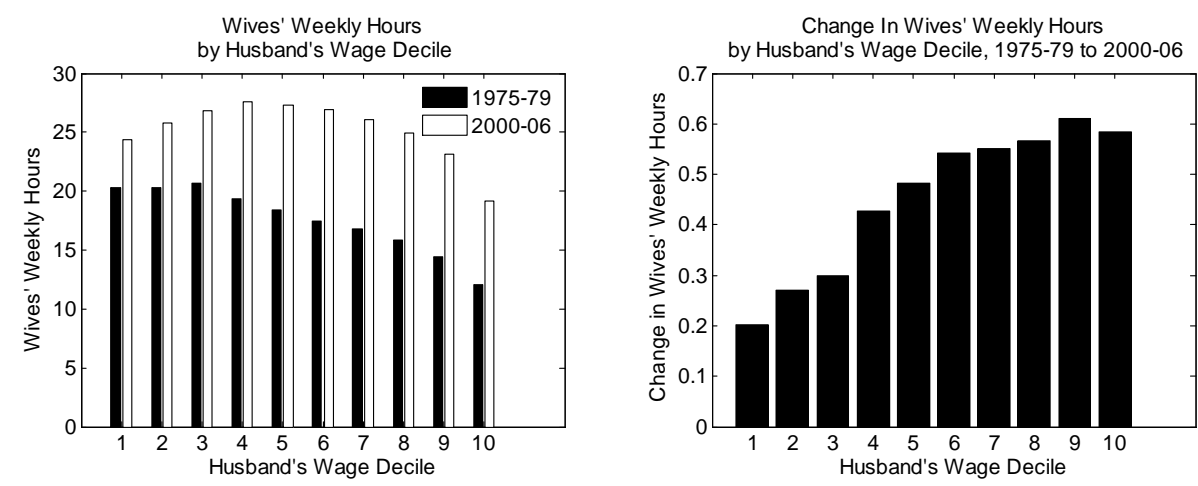

1. The aggregate pattern of wives' hours by the husband's wage has changed from downward-sloping to hump-shaped.

2. The increase in hours worked of wives has been strongly nonuniform among all groups of married women, with increases in hours of wives of middle- and high-wage men being more pronounced than for wives of men married to low-wage husbands.

In this paper, we seek to explain these developments as a result of changes in the wage structure in the economy. Specifically, the aggregate pattern of wives' hours by the husband's wage predicted by our model will depend on the joint distribution of wages in marriages, i.e. on the marginal distributions of gender-specific wages together with the association between spouses' wages.

While most studies focused on assortative mating along education levels (see e.g. Mare 1991, Fernández, Guner, and Knowles 2005, Schwartz and Mare 2005, and Schwartz 2010), we consider sorting in terms of spousal wages. Thereby we face the problem that, in the data, we can observe an individual's wage only if the person is participating in the labor market. In our model, by contrast, wages are measures of earnings potentials. To measure assortative mating in terms of potential wages, we therefore have to impute wages for non-working individuals.

Our model implies that the participation decision is not random. We therefore need to predict wages for non-working wives that would be observed in the absence of non-participation. To do so, we use a 
Heckman $(1976,1979)$ selection model. The Heckman model is estimated separately for the periods 1975-1979, 1980-1984, 1985-1989, 1990-1994, 1995-1999, and 2000-2006. ${ }^{2}$ Appendix B presents details on the wage imputation.

When measuring assortative mating, one has to take into account that simple correlation coefficients between the absolute levels of the variable of interest can be poor measures for describing trends in assortative mating, see Mare (1991) and Hou and Myles (2007). The problem of correlation coefficients is their inability to distinguish changes in the marginal distributions of husbands' and wives' wages from changes in the association between spousal wages. For example, the correlation coefficient between absolute wages would change in response a change in the marginal distributions even when the association between spousal wages were unchanged.

We overcome this problem by calculating the correlation between husband's and wife's position in the respective gender-specific wage distribution, rather than between the absolute levels of their wages. Specifically, we consider the association between spouses' decile positions in the gender-specific wage distributions. At each point in time, there are $10 \%$ of individuals of a given gender in each wage decile independent of the wages earned in the specific decile. Thus, the distribution of decile positions is by construction constant over time. Changes in the correlation between these relative positions of husband and wife therefore reflect changes in assortative mating. ${ }^{3}$

Figure 2 shows the change in the correlation coefficient between husband's and wife's wage decile positions over time for different approaches to handle the missing-data problem. Both for simple regression-based and Heckman-based imputation, respectively, there is a pronounced and steady increase in the correlation coefficient between spousal wage decile positions. In fact, the correlation coefficient almost doubles from 1975-

\footnotetext{
${ }^{2}$ To check for robustness, we also consider alternative ways to handle the missingdata problem. A first strategy is to delete the entire couple from the sample if one of the spouses' wages is not observed. We refer to this specification as 'listwise deletion'. A second strategy is to use wage predictions from simple OLS estimates.

${ }^{3}$ An alternative approach to disentangle changes in the association from changes in the marginal wage distributions is to estimate a crossings model, see e.g. Mare (1991) and Schwartz (2010). An advantage of measuring assortative mating in terms of wage decile positions is that this association has a structural interpretation and can be used directly as an input in our model later on.
} 
Figure 2: Correlation coefficient between spousal wage decile positions.

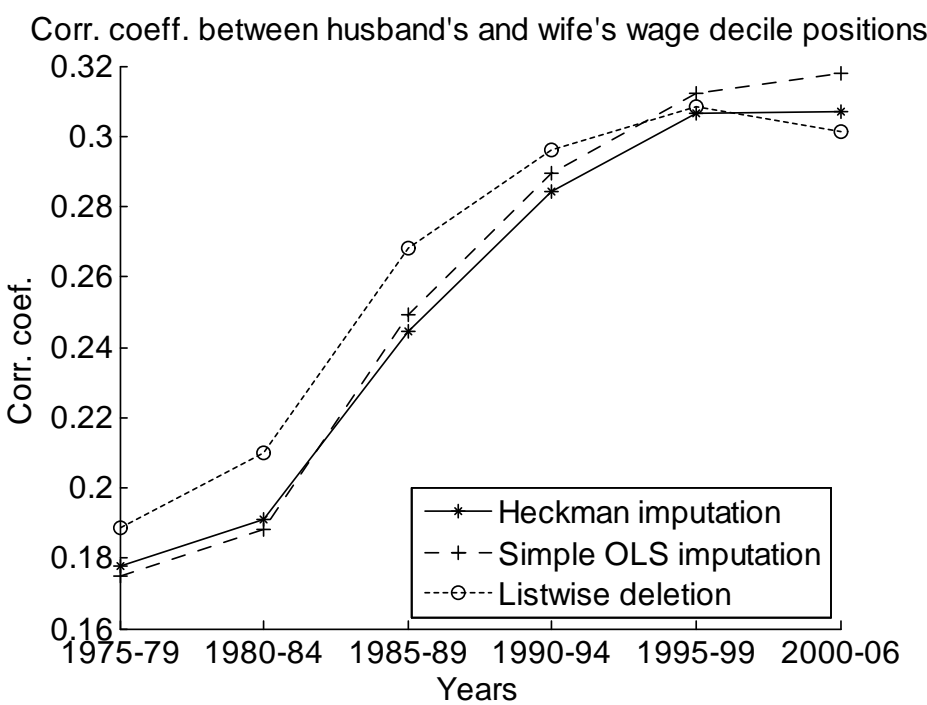

79 to $2000-06$. When we abstain from imputing wages and restrict the sample to couples were both husband and wife are participating, we find a similar development with a marked increase in the wage correlation between 1975-79 and 1995-99.

It is instructive to investigate in more detail the joint distribution of spousal wage decile positions. This allows us to see in which areas of the distribution the association between husband's and wife's wage decile positions has become stronger over time. We summarize the association between spousal wages by a $10 \times 10$ association matrix $S$ containing the observed frequencies of the 100 possible combinations of spouses' wage deciles. Entry $s_{i j}$ in this matrix gives the fraction of marriages in which the husband belongs to the $i$ 'th decile of the male wage distribution while the wife is in the $j$ 'th decile of the female wage distribution. 


\begin{tabular}{|c|c|c|c|c|c|c|c|c|c|c|}
\hline 寻 & 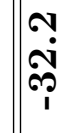 & 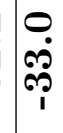 & $\begin{array}{l}\nabla ! \\
\dot{0} \\
\sim \\
1\end{array}$ & 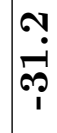 & 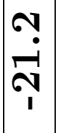 & $\mid \begin{array}{l}\infty \\
\dot{0} \\
1 \\
1\end{array}$ & 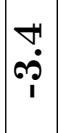 & $\begin{array}{l}r \\
\infty \\
-1\end{array}$ & 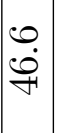 & 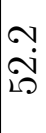 \\
\hline बै & $\underset{\substack{\infty \\
\hdashline}}{\infty}$ & $\mid \begin{array}{l}0 \\
\dot{0} \\
1 \\
1\end{array}$ & Pִ & هִ & $\stackrel{\Re}{\stackrel{\Re}{二}}$ & 亗 & $\begin{array}{l}0 \\
\stackrel{1}{N} \\
\text { N }\end{array}$ & $\overrightarrow{\dot{\leftrightarrow}}$ & $\ddot{0}$ & 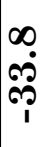 \\
\hline$\frac{\mathcal{T}}{\infty}$ & po & $\stackrel{\sim}{\stackrel{\sim}{*}}$ & 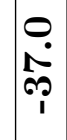 & ִָ & $\begin{array}{l}\boldsymbol{N} \\
\mathfrak{0} \\
1\end{array}$ & $\begin{array}{l}\tilde{H}^{\prime} \\
\dot{0}\end{array}$ & ?ִ & 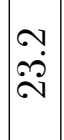 & $\mid \begin{array}{c}0 \\
\dot{m} \\
\infty\end{array}$ & $\begin{array}{l}0 \\
\dot{0}\end{array}$ \\
\hline 蛋 & 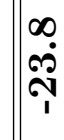 & 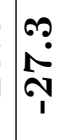 & $\begin{array}{c}0 \\
0 \\
\stackrel{0}{1} \\
1\end{array}$ & 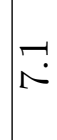 & $\begin{array}{l}\stackrel{y}{\infty} \\
\infty\end{array}$ & $\begin{array}{c}0 \\
\infty\end{array}$ & 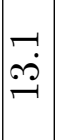 & 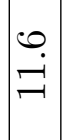 & $\mid \begin{array}{c}0 \\
\dot{L} \\
-1 \\
\end{array}$ & 文 \\
\hline 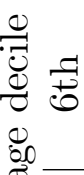 & $\stackrel{\circ}{-}$ & $\stackrel{\vec{\rho}}{\vec{\rho}}$ & $\begin{array}{c}0 \\
0 \\
10\end{array}$ & $\begin{array}{l}20 \\
\infty \\
\infty \\
\infty\end{array}$ & $\vec{\sigma}$ & $\begin{array}{l}\infty \\
\dot{0}\end{array}$ & $\begin{array}{l}\nabla ! \\
\infty \\
1\end{array}$ & $\begin{array}{l}\boldsymbol{r} \\
0 \\
0 \\
1 \\
1\end{array}$ & 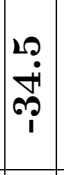 & 苟 \\
\hline 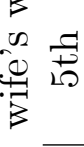 & $\mid \begin{array}{r}+ \\
\end{array}$ & $\stackrel{\Re}{\rightleftharpoons}$ & $\mid \begin{array}{l}\infty \\
\stackrel{\sim}{二}\end{array}$ & $\underset{\sim}{\vec{r}}$ & $\begin{array}{l}20 \\
\sim \\
\sim\end{array}$ & \begin{tabular}{l}
\multirow{2}{*}{} \\
$\dot{10}$
\end{tabular} & ف1 & 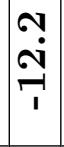 & $\begin{array}{c}\infty \\
\infty \\
1 \\
1\end{array}$ & $\vec{\sim}$ \\
\hline 괌 & $\mid \begin{array}{ll}7 \\
10\end{array}$ & $\begin{array}{l}m \\
\stackrel{2}{S} \\
\stackrel{S}{S}\end{array}$ & $\left|\begin{array}{c}0 \\
\stackrel{0}{二}\end{array}\right|$ & 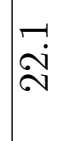 & $\stackrel{0}{0}$ & فํ. & $\begin{array}{l}0 \\
\dot{0} \\
\dot{1}\end{array}$ & $\begin{array}{l}10 \\
0 \\
7 \\
1\end{array}$ & $\mid$\begin{tabular}{c|}
-1 \\
$\ddot{2}$ \\
$\overrightarrow{1}$ \\
1
\end{tabular} & $\begin{array}{l}0 \\
\dot{0} \\
\stackrel{0}{N}\end{array}$ \\
\hline D. & $\stackrel{\sim}{\stackrel{N}{*}}$ & $\mid \begin{array}{l}0 \\
0 \\
1\end{array}$ & $\underset{\sim}{\ddot{\sim}}$ & ִָ & $\begin{array}{l}10 \\
0 \\
0\end{array}$ & $\underset{\sim}{\sim}$ & $\stackrel{-1}{\stackrel{1}{20}}$ & \begin{tabular}{l}
$\boldsymbol{N}$ \\
\hdashline \\
\end{tabular} & 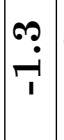 & 09: \\
\hline त् & $\stackrel{12}{\beth}$ & $\begin{array}{l}1 \\
0 \\
-0\end{array}$ & $\begin{array}{l}0 \\
20\end{array}$ & $\stackrel{\sim}{\sim}$ & $\stackrel{\longrightarrow}{\longrightarrow}$ & 몀 & $\begin{array}{l}0 \\
0 \\
\stackrel{1}{-1} \\
1\end{array}$ & 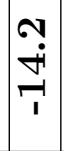 & 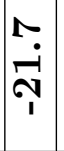 & $\begin{array}{l}\infty \\
\infty \\
+ \\
\end{array}$ \\
\hline$\sqrt{0}$ & $\begin{array}{l}0 \\
\dot{0} \\
\forall\end{array}$ & $\underset{\stackrel{N}{N}}{\stackrel{O}{N}}$ & $\begin{array}{l}\infty \\
\dot{p} \\
\dot{p}\end{array}$ & 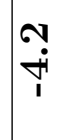 & $\begin{array}{l}0 \\
\dot{0} \\
\stackrel{1}{1}\end{array}$ & 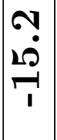 & 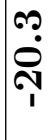 & $\stackrel{\sim}{\stackrel{\sim}{N}}$ & $\begin{array}{c}0 \\
\stackrel{0}{2} \\
\stackrel{2}{1}\end{array}$ & مُ \\
\hline 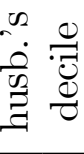 & $\pi$ & స్తు & D. & 韋 & $\frac{7}{10}$ & $\frac{\overrightarrow{1}}{\overrightarrow{0}}$ & $\frac{\pi}{\mathbb{N}}$ & $\frac{\pi}{\infty}$ & $\frac{F}{\sigma}$ & $\stackrel{9}{\stackrel{1}{0}}$ \\
\hline
\end{tabular}


To highlight changes over time, Table 1 shows the relative changes of the frequencies of the different combinations of wage deciles from

1975-79 to 2000-06, $\left(s_{i j}^{2000-06}-s_{i j}^{1975-79}\right) / s_{i j}^{1975-79}$, using the Heckmanimputed wages for non-working wives. ${ }^{4}$ Positive values indicate that in 2000-06 the number of couples with the specific combination of wage deciles has increased relative to 1975-79. Tables 5 and 6 in Appendix $\mathrm{C}$ show the association matrices separately for the two periods of time.

From Table 1 it can be seen that the number of couples where husband and wife differ by much with respect to their relative positions in the respective wage distributions has decreased substantially. For example, the number of couples where the husband is from the top decile of the male distribution and the wife is from the lowest decile of the female distribution has decreased by about 30\%. In general, Table 1 shows a clear pattern that most entries distant from the main diagonal are negative. By contrast, decile combinations on and close to the main diagonal tend to be observed more often, highlighting that couples have become more similar in terms of gender-specific wage positions.

These results show that assortative mating in terms of wages has increased substantially over time. In the next section, we present a theoretical model that highlights the role of changes in the wage structure for explaining the non-uniform increase in hours worked by married women and the resulting change in wives' hours worked disaggregated by the husband's wage decile.

\section{The model}

\subsection{Decision problem of a couple}

We consider an economy populated by couples which differ by the wages of the two spouses. First, we will present the decision process for individual couples. Thereafter, we will aggregate their decisions.

A couple consists of two spouses. We denote spouses' wages by $w_{1}$ and $w_{2}$ and order spouses by these wages such that the index $i=1$ refers to the primary earner and $i=2$ to the secondary earner. Note that the index does not necessarily refer to the gender of the respective spouse. For the decisions at the couple level, gender is not relevant. For instance, labor-force participation of the secondary earner will depend

\footnotetext{
${ }^{4}$ Results using OLS-imputed wages and from listwise deletion are very similar.
} 
on his or her relative wage independent of gender.

There are two commodities in the model, a private "market" consumption good and a "home" consumption good that is public to the couple. We assume that individuals' preferences over the two commodities are characterized by the additively separable utility function

$$
u_{i}=\ln c_{i}+\psi \ln d
$$

where $c_{i}$ denotes consumption of the market good and $d$ stands for consumption of the home or domestic good. $d$ does not wear an index indicating an individual since the home good is public.

Market goods can be earned through market labor by both spouses. We denote the time spent on market work by $n_{i}$. The couple's budget constraint is thus given by

$$
c_{1}+c_{2}=w_{1} \cdot n_{1}+w_{2} \cdot n_{2} \text {. }
$$

Home goods are produced within the household using both spouses' labor (denoted by $h_{1}$ and $h_{2}$, respectively) as inputs with a production function $f\left(h_{1}, h_{2}\right)=\left(h_{1}\right)^{1 / 2}\left(h_{2}\right)^{1 / 2}$. Correspondingly, the home consumption constraint takes the form

$$
d=\left(h_{1}\right)^{1 / 2}\left(h_{2}\right)^{1 / 2} .
$$

We impose equal exponents on both labor inputs. A priori, there is therefore no difference between the two spouses' labor in home production. However, the household can decide to use the two inputs in different quantities depending on opportunity costs.

Both spouses have a time endowment of 1 which can be used for market work and home production, i.e.

$$
n_{i}+h_{i}=1, i=1,2 .
$$

The couple chooses the time allocations of both spouses and the distribution of the resulting consumption possibilities. Thus the couple chooses $h_{1}, h_{2}, n_{1}, n_{2}, d, c_{1}$, and $c_{2}$. Constraints are given by equations (2) to (4).

While the distribution of market consumption is subject to the specific process of household bargaining, we can determine the time allocations by efficiency considerations alone. Since the focus of this paper is 
on labor-supply decisions, we do not need to specify a household bargaining process. For our purposes, it is sufficient to assume that the outcome of the bargaining process is efficient.

\subsection{Decision making}

In collective models of household behavior, households are assumed to allocate their resources efficiently (Chiappori 1988; Chiappori 1992). Consequently, given a desired amount of home consumption, the household will produce it with minimal opportunity costs. Given the desired level of home consumption, the cost minimization determines time spent in home production for both spouses. In our set-up, spouses spend their remaining time on paid market work. Accordingly, we proceed by solving for a family's optimal level of home consumption and then deduce labor-supply decisions.

For efficiency, the marginal costs to produce the public home good (in terms of foregone market consumption) has to be equal to the sum of both spouses marginal rates of substitution which corresponds to Samuelson's (1955) rule for efficient public-good provision,

$$
M R S_{1}\left(c_{1}, d\right)+M R S_{2}\left(c_{2}, d\right)=M C(d),
$$

where $M R S_{i}\left(c_{i}, d\right)=\frac{\partial u_{i}}{\partial c_{i}} / \frac{\partial u_{i}}{\partial d}$ is spouse $i$ 's marginal rate of substitution between home and market goods. $M C(d)$ denotes the marginal costs of home production for the couple in terms of market goods. In order to determine the optimal level of home consumption which satisfies (5), we need to consider the couples' marginal costs of producing the home good as well as spouses' marginal rates of substitution. Detailed derivations of decisions at the couple level can be found in Appendix D.1.

Marginal costs of home consumption. The marginal cost function $M C(d)$ results from the production of $d$ units of the home good with minimal costs. In this minimization problem, the household has to respect that no member can work more than one unit of time in home production:

$$
\begin{aligned}
& h_{1} \leq 1 \\
& h_{2} \leq 1
\end{aligned}
$$

In efficient allocations, total opportunity costs of home production as a function of the consumption level $d$ are the value function of the mini- 
mization problem

$$
\min _{h_{1}, h_{2}} w_{1} h_{1}+w_{2} h_{2}
$$

subject to the home production function (3) and the two time constraints (6) and (7). Technically, marginal costs are the derivative of this value function.

Due to the inequality restrictions (6) and (7), the marginal cost function is not globally differentiable. In the range where (6) and (7) do not bind, production of the home good exhibits constant marginal costs due to the constant returns to scale property of the production function. Marginal costs in this range are given by $2 \cdot\left(w_{1}\right)^{1 / 2} \cdot\left(w_{2}\right)^{1 / 2}$. The costminimal time inputs are $h_{1}=\left(\frac{w_{1}}{w_{2}}\right)^{-1 / 2} \cdot d$ and $h_{2}=\left(\frac{w_{1}}{w_{2}}\right)^{1 / 2} \cdot d$.

The couple can only produce with constant returns to scale and thus with constant marginal costs as long as both spouses can still increase their time spent in home production. From the point where one spouse spends her or his entire time endowment in home production, further increases in home production can only be realized by increases in the other spouse's time input. Since $w_{1}>w_{2}$, the time constraint of the secondary earner (7) will be binding first. This is at the point where $d=\left(\frac{w_{2}}{w_{1}}\right)^{1 / 2}$. From there on, marginal costs are given by the inverse of the primary earner's marginal productivity multiplied by his or her wage. Since $h_{2}=1$ in this range, the marginal productivity of the primary earner is given by $\frac{1}{2}\left(h_{1}\right)^{-1 / 2}$. For $d>\left(\frac{w_{2}}{w_{1}}\right)^{1 / 2}$, the required amount of $h_{1}$ to produce $d$ is $h_{1}=d^{2}$. Marginal costs are therefore $2 \cdot w_{1} \cdot d$ in this range. Since both spouses' time endowments are 1, the maximum quantity of home consumption is 1 . The marginal cost function (in terms of foregone market consumption) is thus given by

$$
M C(d)= \begin{cases}2 \cdot\left(w_{1}\right)^{1 / 2} \cdot\left(w_{2}\right)^{1 / 2}, & d<\left(\frac{w_{2}}{w_{1}}\right)^{1 / 2} \\ 2 \cdot w_{1} \cdot d, & \left(\frac{w_{2}}{w_{1}}\right)^{1 / 2}<d<1 \\ \infty, & d>1 .\end{cases}
$$


The corresponding total (opportunity) cost function is

$$
C(d)= \begin{cases}2 \cdot\left(w_{1}\right)^{1 / 2} \cdot\left(w_{2}\right)^{1 / 2} \cdot d, & d<\left(\frac{w_{2}}{w_{1}}\right)^{1 / 2} \\ w_{2}+w_{1} \cdot d^{2}, & \left(\frac{w_{2}}{w_{1}}\right)^{1 / 2}<d<1 \\ \infty, & d>1 .\end{cases}
$$

Sum of the marginal rates of substitution. We now turn to the spouses' marginal rates of substitution between market and home consumption. The marginal rates of substitution depend on spouses' individual marginal utility of market consumption. The couples's marginal willingness to pay will therefore in general depend on the intra-couple distribution of private consumption which is subject to bargaining. With log utility, however, intra-household bargaining does not affect the couple's willingness to pay for home consumption. Since the marginal rates of substitution are linear with this specific formulation of utility and the home good is public, marginal rates of substitution can be added up to a function of the couple's total consumption levels of the two goods independent of the distribution across spouses. In particular, it holds that

$$
M R S_{1}\left(c_{1}, d\right)+M R S_{2}\left(c_{2}, d\right)=\psi \cdot \frac{c_{1}}{d}+\psi \cdot \frac{c_{2}}{d}=\psi \cdot \frac{c}{d}
$$

where $c=c_{1}+c_{2}$. Redistributing private consumption lowers one spouses's marginal rate of substitution but increases the other spouse's one by the same amount. Changes in the distribution of private consumption within the couple therefore do not affect the sum of the two marginal rates of substitution.

With efficient production of the home good, the constraints (2), (3), and (4) can be combined to

$$
w_{1}+w_{2}=c+C(d)
$$

Thus, the choice of either $c$ or $d$ determines the other as well. The couple's total level of market consumption, $c$, can then be expressed as $c=w_{1}+w_{2}-C(d)$. We can therefore express the sum of the two marginal rates of substitution (10) as a function of the level of home 
consumption only:

$$
\sum_{i=1}^{2} M R S_{i}= \begin{cases}\psi \frac{w_{1}+w_{2}}{d}-2 \psi\left(w_{1}\right)^{1 / 2} \cdot\left(w_{2}\right)^{1 / 2}, & d<\left(\frac{w_{2}}{w_{1}}\right)^{1 / 2} \\ \psi w_{1}\left(d^{-1}-d\right), & \left(\frac{w_{2}}{w_{1}}\right)^{1 / 2}<d<1 \\ -\infty, & d>1\end{cases}
$$

\subsection{Labor-supply decisions}

By the condition for efficient provision of the public good (5), the optimal level of home consumption is at the intersection of (8) and (11). Labormarket participation of the secondary earner will depend on whether or not the couple wishes a level of home consumption that can be produced without using the entire time endowment of the secondary earner. Technically, the secondary earner will participate if (5) is solved by a $d$ that falls below $\left(\frac{w_{2}}{w_{1}}\right)^{1 / 2}$. We can thus derive a participation condition on the secondary earner's wage relative to the primary earner's one. The participation threshold for the secondary earner is

$$
w_{2}>\frac{\psi}{2} \cdot w_{1}
$$

The secondary earner only participates in the labor market if his or her relative contribution to the couple's potential income exceeds some threshold value determined by the valuation of home consumption. The higher the wage of the primary earner, the higher the wage of the secondary earner has to be for participation of both spouses.

Conditional on participation of the secondary earner, her or his market hours are

$$
n_{2}=\frac{2}{2+\psi}-\frac{\psi}{2+\psi} \cdot \frac{w_{1}}{w_{2}}
$$

and the primary earner's hours are

$$
n_{1}=\frac{2}{2+\psi}-\frac{\psi}{2+\psi} \cdot \frac{w_{2}}{w_{1}} .
$$

If the secondary earner does not participate, the primary earner works constant hours on the market, given by

$$
n_{1}=\frac{2}{2+\psi} .
$$


Note that none of the labor-supply decisions described by equations (12) to (15) depend on the absolute wage of one of the two spouses. Instead, all decisions depend on the wage ratio between the two spouses within the couple.

Now we consider a couple with a wife $F$ and husband $M$, whose wages are denoted by $w_{F}$ and $w_{M}$, respectively. The wife is the secondary earner if $w_{F}<w_{M}$ and vice versa. Summarizing labor-supply decisions at the couple level as described by equations (12) to (15), we can express hours worked by a wife $F$ as a function of the wage ratio within the couple, $\omega=\frac{w_{F}}{w_{M}}$,

$$
n_{F}(\omega)= \begin{cases}0, & \omega<\frac{\psi}{2} \\ \frac{2}{2+\psi}-\frac{\psi}{2+\psi} \cdot \omega^{-1}, & \frac{\psi}{2} \leq \omega<\frac{2}{\psi} . \\ \frac{2}{2+\psi}, & \omega \geq \frac{2}{\psi}\end{cases}
$$

We impose the parameter restriction

$$
\psi<2
$$

such that there are wage ratios for which both, husband and wife, participate in the labor market, see equation (16).

\subsection{The role of assortative mating}

We now illustrate the influence of the mating structure on the aggregate pattern of wives' labor supply. In the next section, we aggregate individual decisions formally to obtain the aggregate pattern of wives' hours by the husband's wage predicted by our model.

Equation (16) describes the relation between the husband's wage and the wife's labor supply at the household level. This relation is negative and independent of the mating structure. By contrast, the aggregate pattern of wives' hours by the husband's wage also depends on assortative mating because assortative mating affects the aggregation of individual decisions.

Figure 3 illustrates the relation between wife's hours and the wages of the two spouses in the couple given by equation (16). The figure shows some selected iso-hours lines where darker colors correspond to more hours of the wife. The dark gray area in the upper left part of the figure contains couples who decide that only the wife works for pay. In 
Figure 3: Wives' hours of market work for different husband-wife wage combinations (iso-hours lines and areas, resp.; the darker, the more hours) and two joint distributions of wages with identical marginal distributions (scenario 1: imperfect sorting (non-filled circles); scenario 2: perfect sorting (filled circles)).

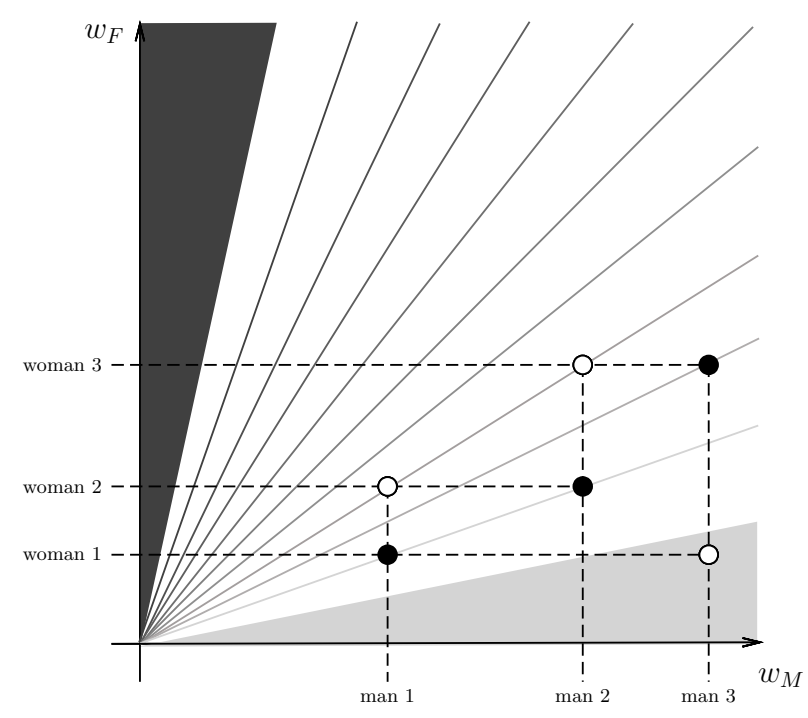

the light gray area in the lower right corner of the figure, wives do not participate in the labor market. Between these two areas, hours of wives continuously decrease from the upper left to the lower right as the wife's relative wage decreases.

The circles in the figure indicate couples with different husband-wife wage combinations. We illustrate the role of assortative mating on the aggregate pattern of labor supply using these couples as examples. We consider three women and three men who are matched to each other in two different ways. Across scenarios, the gender-specific marginal distributions of wages are identical but the joint distribution of spousal wages differs. In scenario 1 (non-filled circles), marital sorting is imperfect while it is perfect in scenario 2 (filled circles). Marital sorting is perfect in the second scenario as the woman with the highest potential wage (woman 3) is married to the man with the highest wage (man 3), and so on. 
First note that, in the example, the increase in assortative mating alters the aggregate participation rate. In scenario 1, the couple in the lower right of the figure (woman 1 and man 3) decides against labormarket participation of the wife. Intra-household wage differentials are sufficiently pronounced that it is rational to use the wife's time solely in home production. In the other two couples, both spouses participate on the labor market. The aggregate participation rate of wives is $2 / 3$ in this scenario.

In scenario 2 (filled circles), although the marginal distributions of wages have not changed, the aggregate participation rate is 1 . Sorting is perfect in this scenario, i.e. the top-wage wife is matched with the top-wage husband and so on. As a consequence, in the example, there is no more couple where intra-household wage differentials are sufficiently large for husband-only participation.

Changes in assortative mating affect the aggregate pattern of wives' hours worked by the husband's wage positions. In scenario 1, the wife married to the husband with the highest wage (man 3) works the fewest hours while the other two women work the same. In scenario 2 , this pattern is flipped upside down with the wife married to the top-wage husband supplying the most labor and the other two women working the same.

\subsection{Aggregate pattern of wives' hours by the hus- band's wage positions}

We now use our model for a stratification analysis as performed in Section 2 for the CPS data. Specifically, we study the aggregate pattern of wives' hours by the husband's wage predicted by our model for different forms of assortative mating.

We can use the joint distribution of wages in marriages as an input to our model, i.e. the marginal distributions of gender-specific wages and the association between spouses' wages. We allow for the possibility that the marginal distributions are not the same across genders. Specifically, we allow for a gender wage gap. To highlight the role of changes in the association between husband's and wife's wages, we consider uniform marginal distributions in the theoretical part of the paper. In the next section, we feed the empirically observed marginal and joint distributions of wages into our model. 
In general, marginal distributions may differ by gender. With a gender wage gap, the wage of the representative man in the $i$ 'th decile of the male distribution, $W_{M}(i)$, is higher than the wage of the representative woman in the $i$ 'th decile of the female distribution, $W_{F}(i)$. We denote the absolute difference between gender-specific wages by $\alpha$ and assume here that this wage gap is constant across deciles.

We normalize the marginal distribution of female wages so that its support has length 1, i.e. female wages are distributed uniformly on $\left(w_{\min }, w_{\min }+1\right)$ with $w_{\min } \geq 0$. Correspondingly, male wages are distributed uniformly on $\left(w_{\min }+\alpha, w_{\min }+1+\alpha\right)$. We apply the parameter restriction

$$
\frac{w_{\min }}{w_{\min }+\alpha} \geq \frac{\psi}{2}
$$

which ensures that in a couple where both husband and wife earn the lowest gender-specific wages, respectively, the wife participates in the labor market. It furthermore implies that, whenever husband and wife are at the same quantile of the respective wage distributions, both spouses participate.

We model assortative mating similar as in Kremer (1997). It is assumed that a proportion $\xi$ of agents marries a spouse from the same wage quantile whereas everyone else marries randomly. Perfect sorting and random mating are special cases where $\xi=1$ or $\xi=0$, respectively. For a husband with wage $w_{M}$, the probability of being married to a wife with wage $w_{F}=w_{M}-\alpha$ is $\xi$ while all other wages of the wife are equally likely with a total probability of $1-\xi$.

The economy-wide pattern of wives' hours by the husband's wage positions results from (i) the relation between the husband's wage and the wife's labor supply at the household level described by equation (16) and (ii) the mating structure in the economy. To determine the aggregate pattern, we calculate average hours of wives married to husbands earning a certain wage $w_{M}$. We do so by integrating individual decisions (16) taking into account the density function of wages, $\bar{n}_{F}\left(w_{M}\right)=\int n_{F}\left(\frac{w_{F}}{w_{M}}\right) \cdot f\left(w_{F} \mid w_{M}\right) \mathrm{d} w_{F}$, where $\bar{n}_{F}\left(w_{M}\right)$ denotes average hours worked of wives married to husbands earning a wage $w_{M}$. The densities $f\left(w_{F} \mid w_{M}\right)$ depend on assortative mating. Given the marginal and joint distributions of wages, average hours of wives married to hus- 
bands earning a wage $w_{M}$ are

$$
\begin{aligned}
\bar{n}_{F}\left(w_{M}\right)= & \underbrace{(1-\xi) \cdot \int_{w_{\min }}^{\frac{\psi}{2} w_{M}} 0 \mathrm{~d} w_{F}}_{\text {no participation of wife }} \\
& +\underbrace{(1-\xi) \cdot \int_{\frac{\psi}{2} w_{M}}^{\frac{2}{\psi} w_{M}}\left[\frac{2}{2+\psi}-\frac{\psi}{2+\psi} \cdot \frac{w_{M}}{w_{F}}\right] \mathrm{d} w_{F}}_{\text {only wife participates }} \\
& +\underbrace{(1-\xi) \cdot \int_{\frac{2}{\psi} w_{M}}^{w_{\min }+1} \frac{2}{2+\psi} \mathrm{d} w_{F}}_{\text {both spouses participate }} \\
& \underbrace{\underbrace{2+\frac{\psi}{2+\psi}}_{2+\psi} \cdot \frac{w_{M}}{w_{M}-\alpha}]}_{\text {fraction marrying perfectly assortatively, both participate }}
\end{aligned}
$$

which evaluates as (see Appendix D.2)

$$
\bar{n}_{F}\left(w_{M}\right)=\Psi+(1-\xi) \cdot g\left(w_{M}\right)+\xi \cdot k\left(w_{M}\right)
$$

where $\Psi=\frac{2}{2+\psi}+(1-\xi) \cdot \frac{2}{2+\psi} \cdot w_{\min }$ and

$$
\begin{aligned}
& g\left(w_{M}\right)=-\frac{\psi}{2+\psi} \cdot\left(1+\ln \frac{4}{\psi^{2}}\right) \cdot w_{M} \\
& k\left(w_{M}\right)=-\frac{\psi}{2+\psi} \cdot \frac{w_{M}}{w_{M}-\alpha} .
\end{aligned}
$$

Wives' hours by the husband's wage are thus a constant plus the weighted sum of two functions of the husband's wage. $g\left(w_{M}\right)$ is a downward sloping and linear function while $k\left(w_{M}\right)$ is an upward sloping and concave function for $\alpha>0$ and a constant for $\alpha=0$. The weights for $g\left(w_{M}\right)$ and $k\left(w_{M}\right)$ are determined by the parameter $\xi$ measuring the degree of assortative mating. The pattern of wives' hours by the husband's wage decile thus depends on the degree of assortative mating and the gender wage gap.

Figure 4 illustrates the pattern of wives' hours by the husband's wage deciles for six different scenarios. To illustrate the possible patterns, we 
Figure 4: Patterns of wives' hours by husbands' wage deciles for different degrees of assortative mating (illustration using uniform marginal distributions).

no wage gap, $\alpha=0$
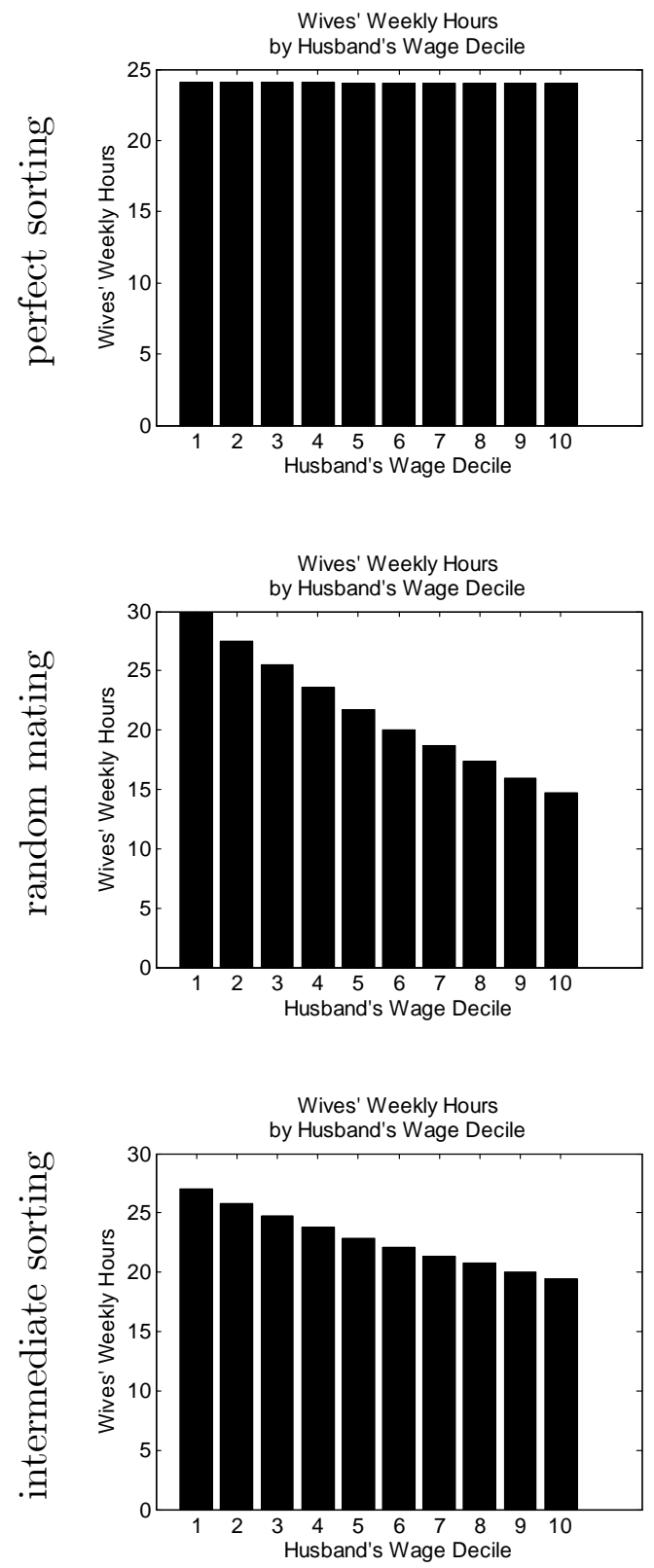

wage gap, $\alpha>0$
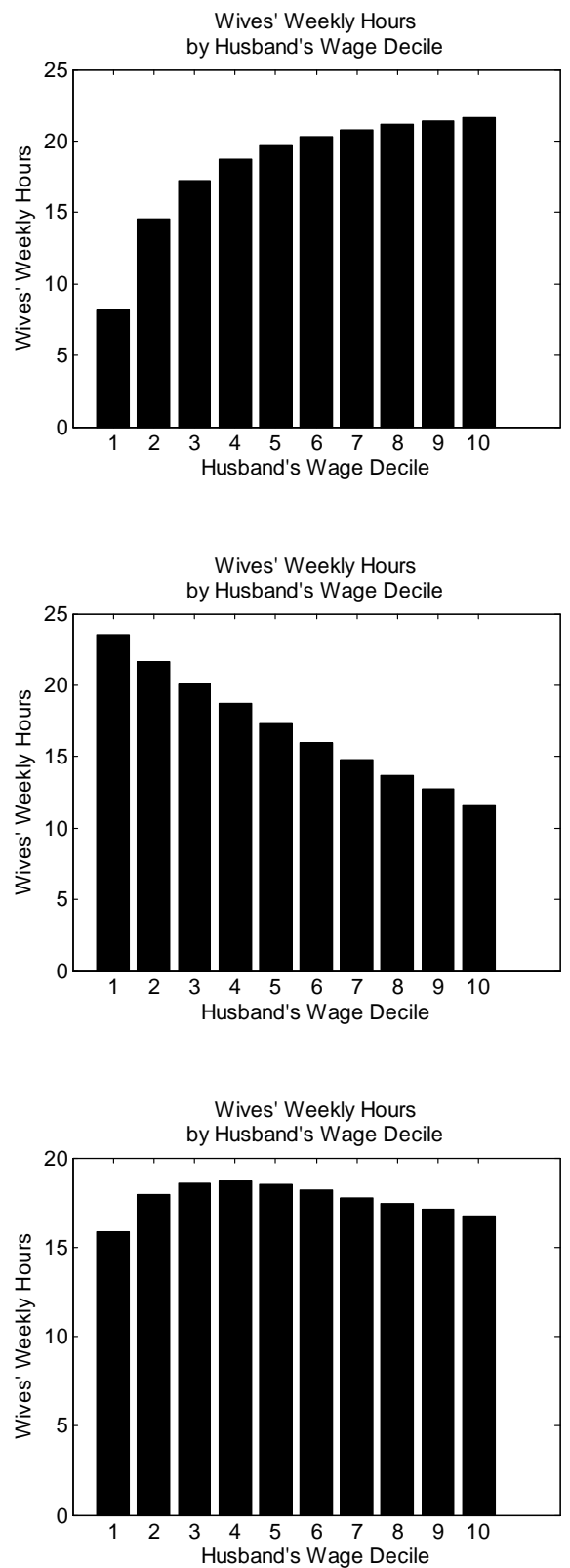
use example parameter values. ${ }^{5}$ When we compare model predictions to empirical observations in the next section, we use the empirically observed marginal and joint distributions of wages.

Here, we distinguish between two cases concerning the wage gap $(\alpha=0, \alpha>0)$ and three different degrees of assortative mating $(\xi=1$, $\xi=0,0<\xi<1)$. The left column in Figure 4 refers to the case of no wage gap $(\alpha=0)$, while the right column shows the results when a wage gap is present $(\alpha>0)$. The rows in Figure 4 refer to the three cases of assortative mating (perfect sorting, random mating, intermediate sorting).

Consider the case of perfect assortative mating, $\xi=1$, which is illustrated in the first row of Figure 4. In this situation, there exist only marriages where both wife and husband are from the same quantile in the respective gender-specific wage distribution.

Without a gender wage gap, $\alpha=0$, this implies that the wage ratio in each couple is $\omega_{j}=1$. Consequently, all wives work the same, which can be seen from equation (18) for $\xi=1$ and $\alpha=0$,

$$
\bar{n}_{F}\left(w_{M}\right)=\Psi-\xi \cdot \frac{\psi}{2+\psi}
$$

This case is illustrated in the upper left panel of Figure 4.

By contrast, when there is a gender wage gap, $\alpha>0$, the average wage ratio, $\left(w_{M}-\alpha\right) / w_{M}$, is increasing in the husband's wage. As a consequence, with a gender wage gap and perfect assortative mating, average hours worked by wives are increasing in the husband's wage. This is illustrated in the upper right panel of Figure 4 and can be seen from equation (18) for $\xi=1$ and $\alpha>0$ :

$$
\bar{n}_{F}\left(w_{M}\right)=\Psi-\xi \cdot \frac{\psi}{2+\psi} \cdot \frac{w_{M}}{w_{M}-\alpha} .
$$

In the other extreme case, $\xi=0$, mating is completely random. Here, all possible combinations of wages within a marriage exist with

\footnotetext{
${ }^{5}$ For the figure, the parameter $\psi$ measuring the valuation of home consumption is set to 0.5 and the marginal distribution of female wages is uniform on $[0.1,1.1]$, thus $w_{\min }=0.1$. For the cases with a gender wage gap (right column), we set $\alpha=0.3$, otherwise $\alpha=0$. The parameter $\xi$ measuring the degree of assortative mating is 1 (first row), 0 (second row), or 0.5 (third row), respectively. The weekly time endowment is set to 40 hours.
} 
same frequency. Hence, every husband is on average married to the wife earning the average female wage $\bar{w}_{F}$ independent of his own wage position. Therefore, the average wage ratio $\bar{w}_{F} / w_{M}$ is decreasing across the male wage distribution. As can be seen from equation (18) for $\xi=$ 0 , this results in a downward-sloping pattern of wives' hours by the husband's wage, independent of the wage gap,

$$
\bar{n}_{F}\left(w_{M}\right)=\Psi-\frac{\psi}{2+\psi} \cdot\left(1+\ln \frac{4}{\psi^{2}}\right) \cdot w_{M} .
$$

This case is illustrated in the second row of Figure 4.

The third row of Figure 4 represents an intermediate case of assortative mating where $\xi=0.5$. In this intermediate case, both functions $g\left(w_{M}\right)$ and $k\left(w_{M}\right)$ are given non-zero weights in equation (18). For $\alpha=0$, wives' hours by the husband's decile are then the sum of a downward sloping function and a constant,

$$
\bar{n}_{F}\left(w_{M}\right)=\Psi-(1-\xi) \cdot \frac{\psi}{2+\psi} \cdot\left(1+\ln \frac{4}{\psi^{2}}\right) \cdot w_{M}-\xi \cdot \frac{\psi}{2+\psi},
$$

and thus downward sloping in the male wage, see the lower left panel of Figure 4 . In the presence of a gender wage gap, $\alpha>0$, female hours by male wage decile are the sum of a downward sloping linear function and a concave upward sloping function,

$\bar{n}_{F}\left(w_{M}\right)=\Psi-(1-\xi) \cdot \frac{\psi}{2+\psi} \cdot\left(1+\ln \frac{4}{\psi^{2}}\right) \cdot w_{M}-\xi \cdot \frac{\psi}{2+\psi} \cdot \frac{w_{M}}{w_{M}-\alpha}$.

The function $n_{F}\left(w_{M}\right)$ is thus concave and can be hump-shaped, depending on the specific value for $\xi$. In Appendix D.3, we show that for any combination of the parameters $\psi, w_{\min }$, and $\alpha>0$, there exists a degree of assortative mating, $\xi$, such that the pattern of wives' hours by the husband's wage is hump-shaped.

The role of assortative mating for the pattern of wives' hours by the husband's wage becomes apparent when comparing the three panels in the right column of Figure 4. In all three scenarios, the marginal distributions of gender-specific wages are identical. However, the patterns in wives' hours differ depending on the association between spouses' wages. 


\section{Quantitative analysis}

The analysis in the previous section has shown that our model is able to generate the empirical patterns documented in Section 2: The aggregate pattern of wives' hours by the husband's wage has been downwardsloping in 1975-79 like in the middle row of Figure 4. In 2000-06 this pattern has changed to being hump-shaped as in the lower right panel of Figure 4.

The patterns in hours predicted by the model depend on the joint distribution of wages in marriages, i.e. on the marginal distributions of gender-specific wages and the association between spouses' wages. We now feed the empirically observed joint distributions of wages into our model and investigate whether observed trends in these distributions imply patterns in hours that are consistent with the empirical developments.

As in Section 2, we measure the association in terms of the number of marriages that exist between different deciles of the gender-specific marginal wage distributions. The $10 \times 10$ association matrix $S$ introduced in Section 2 contains the relative frequencies of the 100 possible combinations of deciles in a marriage. As discussed in Section 2, the association between husband's and wife's wage has changed towards more pronounced assortative mating.

Since we consider deciles, all columns (and all rows) in $S$ contain 10 percent of the overall population. By construction, our analysis in terms of wage deciles controls for changes in the marginal gender-specific wage distributions that could otherwise distort the measurement of changes in assortative mating. Put differently, by measuring assortative mating in terms of wage deciles, we can disentangle changes in the marginal distributions of husband's and wife's wages from changes in the association between spousal wages.

The gender-specific mean wage levels associated with the deciles are denoted by $W_{F}(i)$ and $W_{M}(i)$, respectively, where $i$ is a decile number. Table 2 shows the marginal distributions of spousal wages for the two periods of time we consider, 1975-79 and 2000-06. For both genders, wages have increased over time whereas the increase has been stronger for women. The gender wage gap closed by 12 percentage points on average over all deciles. The table also shows that changes in wages and the gender wage gap have not been uniform across wage deciles. 


\begin{tabular}{|c|c|c|c|}
\hline$\stackrel{9}{5}$ & 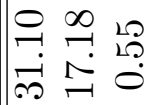 & 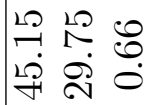 & $\ddot{Z}$ \\
\hline$\frac{\pi}{\sigma}$ & 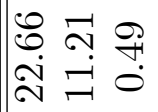 & 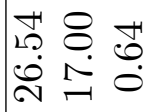 & 足 \\
\hline$\frac{F}{\infty}$ & 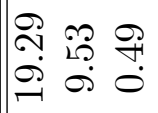 & 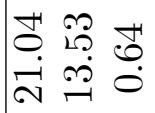 & م્1 \\
\hline$\frac{F}{N}$ & 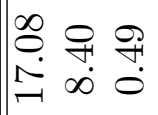 & 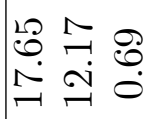 & 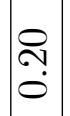 \\
\hline$\frac{0}{0}$ & 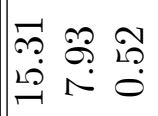 & 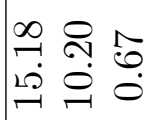 & $\stackrel{20}{-1}$ \\
\hline$\frac{9}{\sqrt{10}}$ & $\mid \begin{array}{ccc}9 & 9 & 0 \\
0 & 0 & 0 \\
\ddot{9} & 1 & 0\end{array}$ & 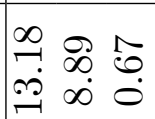 & $\ddot{7}$ \\
\hline 孚 & 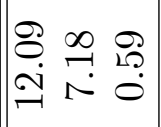 & $\mid$\begin{tabular}{lll}
0 & $N$ & $\infty$ \\
\hdashline & $N$ & 0 \\
$\beth$ & $N$ & 0
\end{tabular} & $\stackrel{g}{\varrho}$ \\
\hline 芴 & 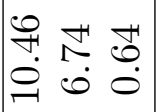 & $\mid \begin{array}{lll}\Re & \infty & \Re \\
0 & 0 & \stackrel{1}{0} \\
\dot{0} & 0 & 0\end{array}$ & $\begin{array}{l}\infty \\
0 \\
0 \\
0\end{array}$ \\
\hline ন্] & $\left|\begin{array}{ccc}0 & \unlhd & \nwarrow \\
\infty & 0 & \Gamma \\
\infty & 0 & 0\end{array}\right|$ & 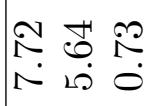 & $\begin{array}{l}\stackrel{\mathscr{O}}{0} \\
\dot{0}\end{array}$ \\
\hline $\overrightarrow{0}$ & 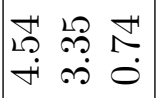 & 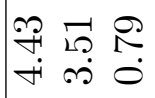 & : \\
\hline 苋 & 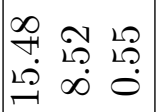 & 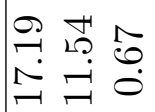 & 궁 \\
\hline & 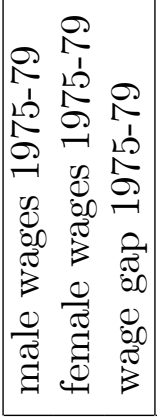 & 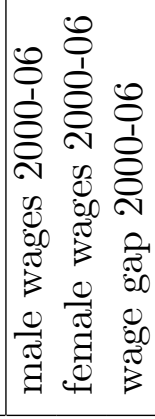 & 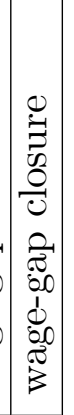 \\
\hline
\end{tabular}


For both genders, wages in the upper deciles have grown stronger than wages in the lower deciles. Similarly, the closure of the gender wage gap has been strongest in the upper half of the wage distribution.

Finally, we have to choose a value for the parameter $\psi$ measuring the valuation of home consumption and a value for the weekly time endowment. We set the relative valuation of home consumption to $\psi=0.5$, a value in the range commonly used in the literature for comparable utility functions, see e.g. Jones, Manuelli, and McGrattan (2003). This value implies that the ratio of time spent on home production and time spent on market work is about $60 \%$, which is in line with empirical findings. For instance, McGrattan, Rogerson, and Wright (1997) estimate a household utility function with home production and their results imply that the ratio of home to market hours is $15 / 27$. The weekly time endowment has a pure scaling effect on labor supply and is set to 40 hours. The weekly time endowment is the total working time of agents in our model since leisure is absent from the model.

To calculate the economy-wide pattern of wives' hours by the husband's wage decile predicted by our model for a given joint distribution of wages $\left\{W_{F}, W_{M}, S\right\}$, we proceed as follows. We first determine female labor supply for all 100 possible combinations of decile positions in a $10 \times 10$ matrix $H$. To determine hours worked by the wife $h_{i j}$ in a specific cell $i j$ we plug the ratio of gender-specific average wages in this cell, $\omega_{i j}=W_{F}(j) / W_{M}(i)$, into equation (16). Average hours worked by wives married to men in decile $i$ are then given by $\left(h_{i} \cdot s_{i}^{\prime}\right) / \sum_{j=1}^{10} s_{i j}$, where $h_{i}$ is the $i$ 'th row of the female hours matrix $H$ and $s_{i}$ is the corresponding row in the association matrix $S$.

Figure 5 shows wives' hours by the husband's wage decile predicted by our model when we use the empirically observed marginal and joint distributions of spousal wages in 1975-79 and 2000-06, respectively. The right panel shows the relative change in married women's hours by the husband's wage decile between the two periods. Thus, the figure is the model's counterpart to the stratification analysis performed using CPS hours displayed in Figure 1.

For 1975-79, the model predicts a decreasing pattern of wives' hours by the husband's wage decile as observed in the data. For 2000-06, the model predicts a higher level of hours worked by wives. From the right panel of the figure, one can see that the predicted increase in hours is not uniform across husband's wage deciles. As in the data, wives 
Figure 5: Predicted wife's weekly hours by husband's wage decile.
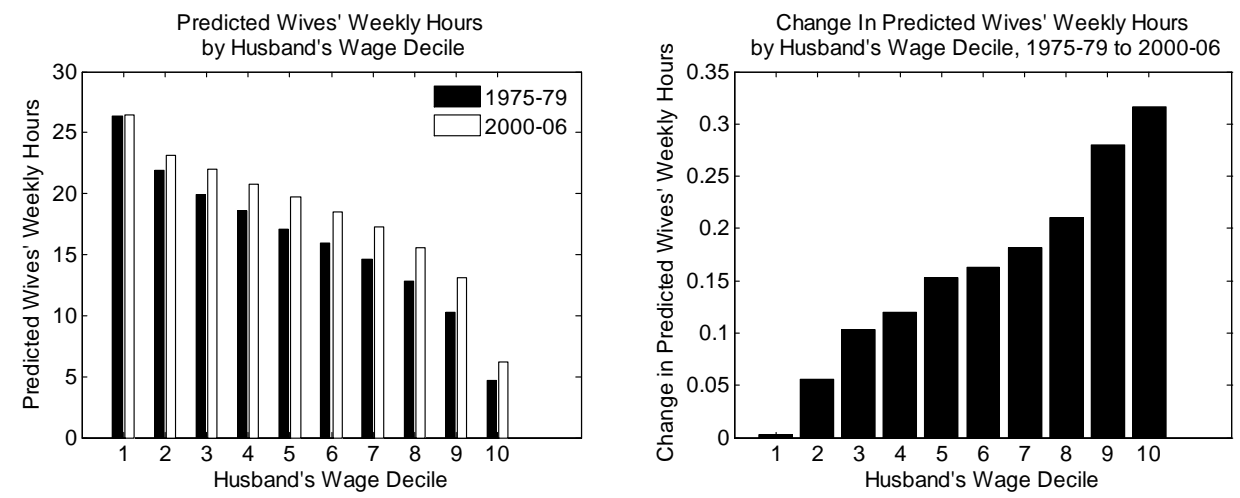

married to high-wage men experience the strongest increases. However, the increase is not sufficiently non-uniform to change the pattern in the left panel from downward sloping to hump-shaped.

The patterns in Figure 5 result from effects of changes in the marginal distributions of gender-specific wages as well as from effects due to changes in the association of spousal wages. To disentangle these effects, we perform a series of counterfactual experiments. Figure 6 summarizes the results. Each panel in the figure corresponds to a different counterfactual setting and shows the change in wives' hours by the husband's decile (the figures are thus the analogs to the right panel in Figure 5).

In a first experiment, we hold constant the association matrix $S$ at its 1975-79 level but allow the marginal distributions to change over time. This way, we shut down effects of trends in assortative mating. From the upper left panel in Figure 6 it can be seen that, when we do not allow for change in assortative mating, the model does predict an increase in hours for all groups of wives. Yet, in this scenario, the increase is strongest for wives married to medium-wage men. By contrast, the data show that wives married to high-wage men have experienced the strongest increases in hours worked.

The upper right panel in Figure 6 refers to the other extreme case where we allow for changes in the association between spousal wages but hold constant the gender-specific marginal wage distributions. In this scenario, changes in wives' hours are increasing in the husband's decile 
Figure 6: Counterfactual experiments.

no change in assortative mating no change in marginal distributions
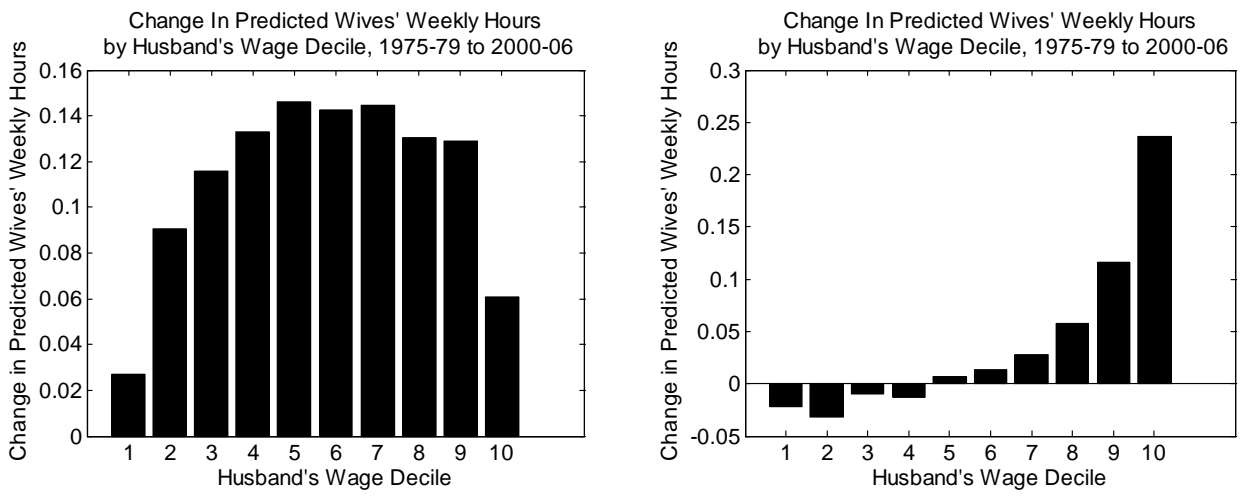

uniform wage-gap closure, no change in assortative mating

uniform wage-gap closure, change in assortative mating
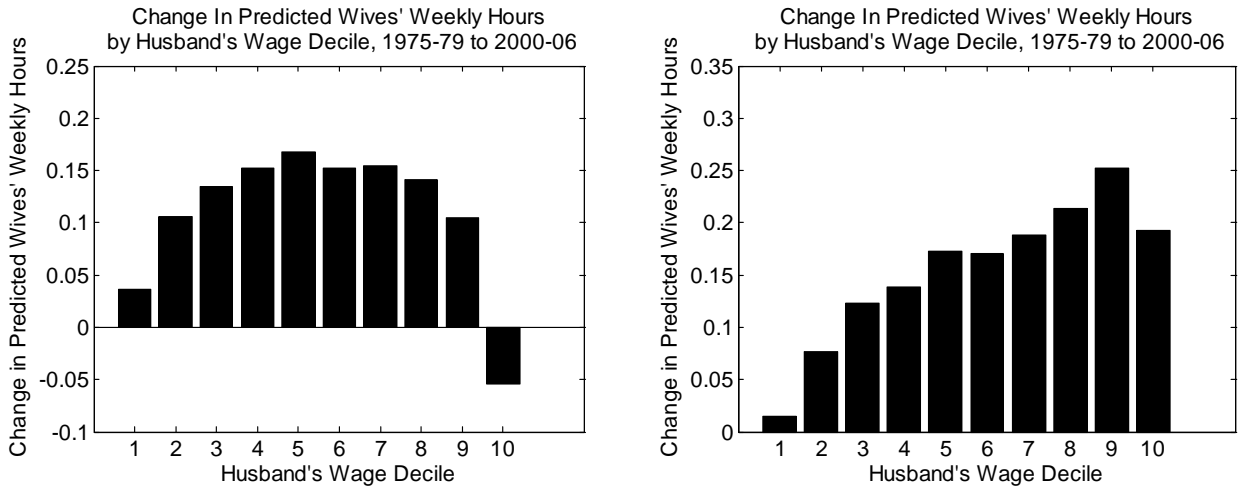
position. Yet, not all groups of wives experience increasing hours in this scenario.

This evaluation of our model suggests that changes in the marginal wage distributions are responsible for the overall increase in hours worked by wives. By contrast, the fact that wives married to high-wage men experienced the most pronounced increase is a result of trends in assortative mating rather than being due to changes in the marginal distributions.

A potential source of the non-uniform increase in hours is that the gender wage gap has closed in a non-uniform way. As we used the empirically observed marginal gender-specific wage distributions, our benchmark results reported in Figure 5 include the effects of the non-uniform wage-gap closure. In order to study the role of this development, we perform two additional counterfactual experiments. In these experiments, we impose a uniform closure of the wage gap, i.e. we impose that the wage gap has closed by the same amount (measured in percentage points) across all deciles.

The lower left panel in Figure 6 refers to the case where the wage gap closes in such uniform way and the association is held constant at its 1975-79 level. The lower right panel also imposes a neutral wage-gap closure but additionally allows for changes in assortative mating over time. The effects of the non-neutrality of the wage gap closure become apparent when comparing the upper left and the lower left panels in the figure. With a uniform closure of the wage gap, the model predicts decreasing hours for wives of top-wage men, opposed to what is observed in the data. However, one can see that accounting for trends in assortative mating is key for understanding the non-uniform increase in wive's hours. Only when we allow the association matrix to change over time, our model predicts an increasing pattern in the change of hours worked by women as observed in the data.

\section{Conclusion}

This paper has investigated wives' hours disaggregated by the husband's wage decile. Specifically, we have addressed two empirical observations that have been documented for the US. First, the aggregate pattern

of wives' hours by the husband's wage has changed from downwardsloping to hump-shaped. Second, over time, the increase in hours worked 
of wives has been strongly non-uniform among all groups of married women, with increases in hours of wives of middle- and high-wage men being more pronounced than for wives of men married to low-wage husbands.

We have presented a theoretical model that explicitly considers the role of assortative mating in terms of wages for understanding these developments. Assortative mating determines the wage ratios within individual couples. In our model, the intra-couple wage ratio determines the efficient time allocation of the two spouses. Only when the wife's relative wage is high enough, the couple opts for labor-market participation of both spouses.

Under random mating, every husband is on average married to the wife earning the average female wage independent of his own wage. Therefore, the relative wages are lowest for wives married to top-wage husbands. As a consequence, these wives work the fewest hours. Under random mating, the pattern of wives' hours by the husband's wage decile is therefore negative.

Under perfect sorting, by contrast, there exist only marriages where both wife and husband are from the same quantile in the respective gender-specific wage distribution. The pattern of wives' hours by the husband's wage will then also depend on the marginal distributions of gender-specific wages. When there is a gender wage gap, the wife's relative wage can be increasing in the husband's wage. As a consequence, hours worked by the wife can be increasing in the husband's wage.

For intermediate sorting, the resulting pattern of wives' hours worked by the husband's wage decile is a weighted average of the patterns in the two extreme cases of random and perfect mating, respectively. The resulting economy-wide pattern of wive's hours by the husband's wage decile can therefore be hump-shaped depending on the relative weights of population groups marrying randomly and perfectly assortatively, respectively. Changes in assortative mating thus alter the pattern of wives' hours worked by the husband's wage decile and consequently lead to a non-uniform change in hours worked by wives.

The patterns in hours predicted by our model depend on the joint distribution of wages in marriages. In a quantitative analysis, we have fed the empirically observed joint distributions of wages into our model and have investigated whether observed changes in these distributions imply patterns in hours that are consistent with the empirical develop- 
ments.

The data shows a closure of the gender wage gap and a clear trend towards stronger assortative mating in terms of wages. For 1975-79, the model predicts a decreasing pattern of wives' hours by the husband's wage decile as observed in the data. For 2000-06, the model predicts a higher overall level of hours worked by wives. In accordance with empirical developments, the model-predicted increase in hours is not uniform across husband's wage deciles. As in the data, wives married to high-wage men experience the strongest increases. However, the increase is not sufficiently non-uniform to change the pattern of wives' hours by the husband's wage from downward sloping to hump-shaped.

A series of counterfactual experiments has shown that changes in the marginal wage distributions are responsible for the overall increase in hours worked by wives. By contrast, the fact that wives married to high-wage men experienced the most pronounced increase is a result of trends in assortative mating rather than being due to changes in the marginal wage distributions. Thus, accounting for trends in assortative mating is key for understanding the non-uniform increase in wives' hours. Only when we take into account trends in assortative mating, our model predicts an increasing pattern in the change of hours worked by women as observed in the data.

\section{References}

Apps, P. F. and R. Rees (1997). Collective labor supply and household production. Journal of Political Economy 105(1), 178-90.

Attanasio, O., H. Low, and V. Sánchez-Marcos (2008). Explaining changes in female labor supply in a life-cycle model. American Economic Review 98(4), 1517-1552.

Blau, F. D. and L. M. Kahn (1997). Swimming upstream: Trends in the gender wage differential in 1980s. Journal of Labor Economics 15(1), 1-42.

Blundell, R., P.-A. Chiappori, T. Magnac, and C. Meghir (2007). Collective labour supply: Heterogeneity and non-participation. Review of Economic Studies 74(2), 417-445.

Blundell, R., A. Duncan, and C. Meghir (1998). Estimating labor supply responses using tax reforms. Econometrica 66(4), 827-861. 
Cancian, M. and D. Reed (1998). Assessing the effects of wives' earnings on family income inequality. The Review of Economics and Statistics 80(1), 73-79.

Chiappori, P.-A. (1988). Rational household labor supply. Econometrica 56(1), 63-90.

Chiappori, P.-A. (1992). Collective labor supply and welfare. Journal of Political Economy 100(3), 437-467.

Devereux, P. J. (2004). Changes in Relative Wages and Family Labor Supply. Journal of Human Resources 39(3), 698-722.

Devereux, P. J. (2007). Small-sample bias in synthetic cohort models of labor supply. Journal of Applied Econometrics 22(4), 839-848.

Fernández, R., N. Guner, and J. Knowles (2005). Love and money: A theoretical and empirical analysis of household sorting and inequality. The Quarterly Journal of Economics 120(1), 273-344.

Galor, O. and D. N. Weil (1996). The gender gap, fertility, and growth. American Economic Review 86(3), 374-387.

Heckman, J. J. (1976). The common structure of statistical models of truncation, sample selection and limited dependent variables and a simple estimator for such models. In Annals of Economic and Social Measurement, Volume 5, number 4, NBER Chapters, pp. 120-137. National Bureau of Economic Research.

Heckman, J. J. (1979). Sample selection bias as a specification error. Econometrica 47(1), 153-161.

Herrnstein, R. J. and C. Murray (1994). The Bell Curve: Intelligence and Class Structure in American Life. New York: The Free Press.

Hou, F. and J. Myles (2007, May). The changing role of education in the marriage market: Assortative marriage in canada and the united states since the 1970s. Statistics Canada, Analytical Studies Branch Research Paper 2007299e.

Jaeger, D. A. (1997). Reconciling the old and new census bureau education questions: Recommendations for researchers. Journal of Business 83 Economic Statistics 15(3), 300-309. 
Jones, L., R. Manuelli, and E. McGrattan (2003). Why are married women working so much? Federal Reserve Bank of Minneapolis, Staff Report No. 317.

Juhn, C. and K. M. Murphy (1997). Wage inequality and family labor supply. Journal of Labor Economics 15(1), 72-97.

Kalmijn, M. (1991a). Shifting boundaries: Trends in religious and educational homogamy. American Sociological Review 56(6), 786800.

Kalmijn, M. (1991b). Status homogamy in the united states. The American Journal of Sociology 97(2), 496-523.

Knowles, J. (2007). Why are married men working so much? The macroeconomics of bargaining between spouses. IZA Discussion Paper 2909.

Kremer, M. (1997). How much does sorting increase inequality? Quarterly Journal of Economics 112(1), 115 - 139.

Mare, R. D. (1991). Five decades of educational assortative mating. American Sociological Review 56(1), 15 - 32.

McGrattan, E. R., R. Rogerson, and R. Wright (1997). An equilibrium model of the business cycle with household production and fiscal policy. International Economic Review 38(2), 267-290.

Morissette, R. and F. Hou (2008). Does the labour supply of wives respond to husbands' wages? Canadian evidence from micro data and grouped data. Canadian Journal of Economics 41(4), 11851210 .

Pencavel, J. (1998). Assortative mating by schooling and the work behavior of wives and husbands. American Economic Review 88(2), $326-329$.

Qian, Z. (1998). Changes in assortative mating: The impact of age and education, 1970-1990. Demography 35(3), 279-292.

Qian, Z. and S. H. Preston (1993). Changes in american marriage, 1972 to 1987: Availability and forces of attraction by age and education. American Sociological Review 58(4), 482-495. 
Samuelson, P. A. (1955). Diagrammatic exposition of a theory of public expenditure. The Review of Economics and Statistics 37(4), $350-356$.

Schwartz, C. R. (2010). Earnings inequality and the changing association between spouses' earnings. American Journal of Sociology 115(5), 1524-1557.

Schwartz, C. R. and R. D. Mare (2005). Trends in educational assortative marriage from 1940 to 2003. Demography 42(4), 621 646.

Sweeney, M. M. and M. Cancian (2004). The changing importance of white women's economic prospects for assortative mating. Journal of Marriage and Family 66(4), 1015-1028.

Sánchez-Marcos, V. (2008). What accounts for the increase in college attainment of women? Applied Economics Letters 15(1), 41-44.

Wooldridge, J. M. (2002). Econometric Analysis of Cross Section and Panel Data. MIT Press.

\section{Appendix}

\section{A CPS data}

The CPS data we use are in the format arranged by Unicon Research. ${ }^{6}$ The CPS is a monthly household survey conducted by the Bureau of the Census. Respondents are interviewed to obtain information about the employment status of each member of the household 16 years of age and older. Survey questions covering hours of work, earnings, gender, and marital status are covered in the Annual Social Economic Supplement, the so-called March Supplement Files. The sample of the CPS is representative of the civilian non-institutional population.

Data on hours and earnings is retrospective and refers to the previous year. The CPS data we use covers the period 1975-2006. While the CPS provides data on hours and earnings from 1963 onwards, the number of children in family under age six is not available before 1975. Since the latter variable is used as an instrument for imputing wages for nonworking individuals, our analysis starts in 1975.

\footnotetext{
${ }^{6}$ See http://www.unicon.com/.
} 
Our selected sample comprises civilians aged 30 to 50 . In a set of robustness tests, we checked that our results are robust with respect to the specific age range (detailed results are available on request). We drop people who derive their main income from self-employment and consider only couples where both husband and wife are present in the sample. We identify spouses by the household identification number. To control for outliers, we drop couples where either husband or wife fall in the top $1 \%$ percentile of observed wages.

In 1992, the educational-attainment question in the CPS changed from years of education to degree receipt. Following Jaeger (1997), we harmonized both series and created a measure of educational attainment that takes on four categories: dropouts, high-school graduates, some college, and college graduates. ${ }^{7}$

\section{B Wage imputation}

Since our dataset is very large, we use Heckman's (1979) two-step efficient estimator instead of Maximum likelihood estimation (see Wooldridge 2002 for technical details). The Heckman two-step model can be described as follows. First, we estimate a binomial probit model that predicts the individual's probability of participation in the labor market (selection equation). Second, we use the estimated selection model to construct the hazard rate for sample inclusion. Third, we include the hazard rate as a regressor in the wage equation. When the error term in the selection equation is correlated with the error term in the wage equation, standard regression techniques yield inconsistent estimates while the two-step Heckman procedure yields consistent estimates.

To identify the Heckman model, we need to find factors that determine whether a wife participates in the labor market but are unrelated to a wife's wage. We assume that the likelihood of working is a function of the number of preschool children at home (we code the number of kids as dummy variables). Moreover, we include in the selection equation quadratic terms in age of wife and husband and the levels of education of both partners. The number of preschool children and the characteristics of the husband are only included in the participation equation but

\footnotetext{
${ }^{7}$ This education variable has been created from the CPS variables_educ (19641991, 19 categories, Unicon recoded) and grdatn (1992-2007, 17 categories).
} 


\begin{tabular}{|l|cc|cc|}
\hline & \multicolumn{2}{|c|}{$1975-1979$} & \multicolumn{2}{c|}{$2000-2006$} \\
\hline Wage equation & estimate & std. err. & estimate & std. err. \\
$\log ($ age wife/17) & -0.054 & 0.149 & 1.182 & 0.116 \\
$\log ($ age wife/17) squared & 0.038 & 0.103 & -0.592 & 0.077 \\
education level 2 wife & 0.156 & 0.011 & 0.385 & 0.014 \\
education level 3 wife & 0.257 & 0.013 & 0.600 & 0.014 \\
education level 4 wife & 0.495 & 0.014 & 0.975 & 0.014 \\
intercept & 1.938 & 0.056 & 1.035 & 0.047 \\
year dummies included & & & & \\
\hline Participation equation & & & & \\
log(age wife/17) & 0.105 & 0.280 & 0.338 & 0.235 \\
log(age wife/17) squared & -0.390 & 0.193 & -0.172 & 0.157 \\
log(age husband/17) & -1.493 & 0.301 & -0.797 & 0.256 \\
log(age husband/17) squared & 0.843 & 0.198 & 0.416 & 0.164 \\
education level 2 wife & 0.306 & 0.015 & 0.501 & 0.019 \\
education level 3 wife & 0.451 & 0.020 & 0.712 & 0.019 \\
education level 4 wife & 0.769 & 0.022 & 0.928 & 0.021 \\
education level 2 husband & -0.051 & 0.015 & 0.190 & 0.018 \\
education level 3 husband & -0.070 & 0.019 & 0.181 & 0.019 \\
education level 4 husband & -0.232 & 0.019 & -0.111 & 0.020 \\
2 kids younger than age 6 & -0.655 & 0.013 & -0.443 & 0.011 \\
3 kids younger than age 6 & -1.041 & 0.020 & -0.733 & 0.015 \\
4 kids younger than age 6 & -1.332 & 0.051 & -1.131 & 0.037 \\
5 kids younger than age 6 & -1.765 & 0.173 & -1.392 & 0.131 \\
intercept & 0.626 & 0.090 & 0.215 & 0.088 \\
year dummies included & & & & \\
& & & & \\
(inv. Mills ratio) & -0.017 & 0.018 & 0.295 & 0.018 \\
\hline
\end{tabular}

Table 3: Two-step Estimates of Heckman Selection Model

\begin{tabular}{|l|l|ccccc|}
\hline & Method & Obs. & Mean & Std. Dev. & Min & Max \\
\hline 1975-1979 & Heckman & 64090 & 2.070 & 0.158 & 1.790 & 2.419 \\
& OLS & 64090 & 2.057 & 0.159 & 1.774 & 2.408 \\
\hline \multirow{2}{*}{$2000-2006$} & Heckman & 94352 & 2.183 & 0.307 & 1.376 & 2.618 \\
& OLS & 94352 & 2.334 & 0.277 & 1.665 & 2.729 \\
\hline
\end{tabular}

Table 4: Predictions of Heckman Selection Model vs. OLS imputation 
are omitted from the wage equation. We also control for time effects. In the wage equation, we include a quadratic term in the wife's age and dummy variables for the wife's level of education. By including all variables that determine the wage also in the participation equation, we allow the participation decision to depend implicitly on the wage.

We fit the Heckman model separately for the periods 1975-1979 and 2000-2006. Table 3 summarizes the two-step estimates of the Heckman selection model. The upper part of the table displays the estimates for the parameters in the wage equation while the lower part shows the results for the participation equation. In both equations, we have included time dummies but their point estimates are omitted from the table to save on space.

From the selection equation, it can be seen that more preschool children in the household significantly decrease the probability of participation. The coefficient of the selection term is reported at the bottom of Table 1. While the selection term is found to be insignificant in 19751979 it turns highly significant in the more recent period. This means that a standard regression not taking into account selection will produce inconsistent wage predictions for non-working women, which shows the relevance of incorporating selectivity in the estimation of the wage equation.

Table 4 compares predicted values from the Heckman model with an ordinary regression model without selection adjustment. In the period where the selection term has been found to be insignificant (1975-1979), wage predictions from the Heckman model and uncorrected OLS are fairly similar on average. During 2000-2006, by contrast, simple regression yields predictions that are on average higher than the Heckmancorrected estimates. Specifically, wage predictions of the Heckman model are on average about $6.87 \%$ lower than the regression-based ones. One can also see that the regression prediction shows less variation than the prediction based on the selection model. 


\section{Association matrices}

Table 5 shows the association matrix $S$ between spouses' wage decile positions for the period 1975-79. The association matrix for the period 2000-06 is presented in Table 6. The relative changes of the frequencies of the different combinations of the wage deciles, $\left(s_{i j}^{2000-06}-s_{i j}^{1975-79}\right) / s_{i j}^{1975-79}$, can be found in Table 1 in the main text.

\begin{tabular}{|c||c|c|c|c|c|c|c|c|c|c|}
\hline \multicolumn{1}{|c||}{$\begin{array}{c}\text { husb.'s } \\
\text { decile }\end{array}$} & \multicolumn{1}{c|}{ 1st } & 2nd & 3rd & 4th & 5th & 6th & 7th & 8th & 9th & 10th \\
\hline \hline 1st & 1.61 & 1.64 & 1.46 & 0.96 & 0.84 & 0.74 & 0.75 & 0.73 & 0.65 & 0.62 \\
\hline 2nd & 1.26 & 1.39 & 1.43 & 0.98 & 0.90 & 0.72 & 0.92 & 1.02 & 0.69 & 0.68 \\
\hline 3rd & 1.24 & 1.22 & 1.20 & 0.96 & 0.92 & 0.82 & 0.96 & 1.03 & 0.87 & 0.78 \\
\hline 4th & 1.04 & 1.06 & 1.10 & 0.96 & 0.98 & 0.95 & 0.96 & 0.97 & 1.03 & 0.93 \\
\hline 5th & 0.99 & 0.95 & 1.01 & 1.00 & 0.97 & 1.07 & 0.99 & 1.03 & 0.96 & 1.04 \\
\hline 6th & 0.92 & 0.92 & 0.94 & 1.08 & 0.98 & 1.07 & 0.97 & 0.96 & 0.97 & 1.18 \\
\hline 7th & 0.84 & 0.87 & 0.81 & 1.09 & 1.04 & 1.14 & 0.96 & 1.05 & 1.02 & 1.18 \\
\hline 8th & 0.77 & 0.77 & 0.80 & 1.13 & 1.13 & 1.10 & 1.03 & 0.97 & 1.15 & 1.15 \\
\hline 9th & 0.72 & 0.66 & 0.70 & 0.97 & 1.11 & 1.25 & 1.14 & 1.06 & 1.20 & 1.19 \\
\hline 10th & 0.61 & 0.53 & 0.56 & 0.87 & 1.12 & 1.13 & 1.31 & 1.19 & 1.45 & 1.25 \\
\hline
\end{tabular}

Table 5: Association Matrix $S$ between Spousal Wages in 1975-79. (Entries give percentage frequencies of different decile comibations.)

\begin{tabular}{|c||c|c|c|c|c|c|c|c|c|c|}
\hline \multicolumn{1}{|c||}{$\begin{array}{c}\text { husb.'s } \\
\text { decile }\end{array}$} & \multicolumn{1}{c|}{ 1st } & 2nd & 3rd & 4th & 5th & 6th & 7th & 8th & 9th & 10th \\
\hline \hline 1st & 2.36 & 1.83 & 1.28 & 1.02 & 0.83 & 0.75 & 0.57 & 0.45 & 0.51 & 0.42 \\
\hline 2nd & 1.61 & 1.62 & 1.34 & 1.23 & 1.00 & 0.94 & 0.67 & 0.54 & 0.58 & 0.45 \\
\hline 3rd & 1.19 & 1.29 & 1.22 & 1.15 & 1.08 & 1.23 & 0.81 & 0.65 & 0.81 & 0.58 \\
\hline 4th & 1.00 & 1.08 & 1.12 & 1.17 & 0.96 & 1.32 & 1.03 & 0.78 & 0.90 & 0.64 \\
\hline 5th & 0.83 & 0.96 & 1.07 & 1.09 & 1.00 & 1.17 & 1.03 & 0.96 & 1.07 & 0.82 \\
\hline 6th & 0.78 & 0.84 & 0.98 & 1.02 & 1.03 & 1.11 & 1.05 & 0.96 & 1.28 & 0.95 \\
\hline 7th & 0.67 & 0.78 & 0.93 & 0.99 & 0.99 & 1.05 & 1.09 & 1.07 & 1.31 & 1.14 \\
\hline 8th & 0.64 & 0.66 & 0.79 & 0.91 & 0.99 & 0.92 & 1.15 & 1.20 & 1.38 & 1.37 \\
\hline 9th & 0.51 & 0.52 & 0.69 & 0.78 & 1.02 & 0.82 & 1.32 & 1.40 & 1.20 & 1.74 \\
\hline 10th & 0.43 & 0.43 & 0.59 & 0.64 & 1.09 & 0.69 & 1.28 & 2.00 & 0.96 & 1.90 \\
\hline
\end{tabular}

Table 6: Association Matrix $S$ between Spousal Wages in 2000-06. (Entries give percentage frequencies of different decile comibations.) 


\section{Derivations and proofs}

\section{D.1 Decisions at the couple level}

\section{D.1.1 Marginal costs of home consumption}

To find the marginal cost function of home consumption, we determine the cost function first. Total opportunity costs are given by $C=w_{1} h_{1}+w_{2} h_{2}$ (home production involves labor only but each spouse faces opportunity costs of not working for pay). For the cost function, we determine the quantities $h_{1}$ and $h_{2}$ to produce $d$ units of the home good with minimal costs. This cost minimization problem yields equivalent input combinations as the maximization of output for given costs. The optimization problem involves the home production function $f\left(h_{1}, h_{2}\right)=\left(h_{1}\right)^{1 / 2}\left(h_{2}\right)^{1 / 2}$, time constraints $h_{1} \leq 1, h_{2} \leq 1$, and the total cost function $C=h_{1} w_{1}+h_{2} w_{2}$. When solving the problem, one has to distinguish whether the time constraints are binding or not.

1. If time constraints are not binding, the Lagrangean reads as

$$
\mathcal{L}=\left(h_{1}\right)^{1 / 2}\left(h_{2}\right)^{1 / 2}+\lambda\left[h_{1} w_{1}+h_{2} w_{2}-C\right] .
$$

The first-order conditions are

$$
\begin{aligned}
\frac{\partial L}{\partial h_{1}} & =\frac{1}{2}\left(h_{1}\right)^{-1 / 2}\left(h_{2}\right)^{1 / 2}+\lambda w_{1}=0 \\
\frac{\partial L}{\partial h_{2}} & =\frac{1}{2}\left(h_{1}\right)^{1 / 2}\left(h_{2}\right)^{-1 / 2}+\lambda w_{2}=0
\end{aligned}
$$

which can be simplified to

$$
h_{2}=\frac{w_{1}}{w_{2}} h_{1}
$$

This gives a relation between both spouses' cost-minimal labor inputs in home production. To determine each spouse's time in home production for a given level of home consumption $d$, substitute (20) into the home production function:

$$
d=\left(h_{1}\right)^{1 / 2}\left(\frac{w_{1}}{w_{2}} h_{1}\right)^{1 / 2} \Longleftrightarrow h_{1}=d\left(\frac{w_{1}}{w_{2}}\right)^{-1 / 2}
$$


For the secondary earner, one obtains

$$
h_{2}=\frac{w_{1}}{w_{2}} d\left(\frac{w_{1}}{w_{2}}\right)^{-1 / 2}=d\left(\frac{w_{1}}{w_{2}}\right)^{1 / 2} .
$$

When time constraints are not binding, total opportunity costs of home production are thus given by

$$
\begin{aligned}
C(d) & =h_{1} w_{1}+h_{2} w_{2}=d\left(\frac{w_{1}}{w_{2}}\right)^{-1 / 2} w_{1}+d\left(\frac{w_{1}}{w_{2}}\right)^{1 / 2} w_{2} \\
& =2\left(w_{1}\right)^{1 / 2}\left(w_{2}\right)^{1 / 2} d
\end{aligned}
$$

Marginal costs in this case are

$$
M C(d)=2\left(w_{1}\right)^{1 / 2}\left(w_{2}\right)^{1 / 2} .
$$

2. Now we consider the case where the time constraint for the secondary earner is binding. This is at the point where

$$
h_{2}=d\left(\frac{w_{1}}{w_{2}}\right)^{1 / 2}=1 \Longleftrightarrow d=\left(\frac{w_{2}}{w_{1}}\right)^{1 / 2} .
$$

The production function in this case is

$$
f\left(h_{1}, 1\right)=d=\left(h_{1}\right)^{1 / 2} .
$$

In this range, to produce $d$ units of the home good, the primary earner's time in home production has to be

$$
h_{1}=d^{2} \text {. }
$$

Total opportunity costs in this case are thus

$$
C(d)=h_{1} w_{1}+h_{2} w_{2}=w_{1} d^{2}+w_{2}
$$

and marginal costs are

$$
M C(d)=2 w_{1} d
$$


3. When both time constraints are binding, the household can not achieve a higher level of home consumption. The maximum level of home consumption is

$$
d=1^{1 / 2} \cdot 1^{1 / 2}=1
$$

In summary, the marginal cost function is defined piecewise, see equation (8) in the main text. If time constraints are not binding, marginal costs are constant. If the time constraint of the secondary earner binds, marginal costs are increasing linearly. If both time constraints bind, home production cannot be increased further.

\section{D.1.2 Sum of the marginal rates of substitution}

In general, the sum of the marginal rates of substitution will depend on the intra-household distribution of private consumption, since the individual MRS depend on both consumption goods. However, with log utility (and thus linear marginal utility), the MRS can be simply added up,

$$
M R S_{1}\left(c_{1}, d\right)+M R S_{2}\left(c_{2}, d\right)=\frac{\psi c_{1}}{d}+\frac{\psi c_{2}}{d}=\frac{\psi c}{d},
$$

where $c=c_{1}+c_{2}$. The sum of husband's and wife's MRS involves the couple's total level of market consumption $c$, which is given by the difference between the couple's full income and its expenditures for home production

$$
c=w_{1}+w_{2}-C(d) .
$$

Using total costs of home consumption (9), this can be written as

$$
c= \begin{cases}w_{1}+w_{2}-2 \cdot\left(w_{1}\right)^{1 / 2} \cdot\left(w_{2}\right)^{1 / 2} \cdot d, & d<\left(\frac{w_{2}}{w_{1}}\right)^{1 / 2} \\ w_{1} \cdot\left(1-d^{2}\right), & \left(\frac{w_{2}}{w_{1}}\right)^{1 / 2}<d<1 . \\ -\infty, & d>1 .\end{cases}
$$

Using this expression for $c$, the sum of the MRS can be written as in equation (11) in the main text.

\section{D.1.3 Labor-supply decisions}

To determine labor-supply decisions, we derive the household's efficient level of home consumption which is determined by the intersection of 
equations (8) and (11). Since (8) and (11) are piecewise defined functions, one has to solve for the intersections of the different parts and check whether the intersection lies within the respective range.

1. The intersection of the first parts of (8) and (11) satisfies:

$$
\begin{aligned}
2\left(w_{1}\right)^{1 / 2}\left(w_{2}\right)^{1 / 2} & =\psi \frac{w_{1}+w_{2}-2 \cdot\left(w_{1}\right)^{1 / 2} \cdot\left(w_{2}\right)^{1 / 2} \cdot d}{d} \\
& \Longleftrightarrow d=\frac{\psi}{2+\psi} \cdot \frac{\left[w_{1}+w_{2}\right]}{\left(w_{1}\right)^{1 / 2} \cdot\left(w_{2}\right)^{1 / 2}}
\end{aligned}
$$

This level of $d$ lies in the interval $\left(0,\left(\frac{w_{2}}{w_{1}}\right)^{1 / 2}\right)$ if

$$
\frac{\psi}{2+\psi} \cdot \frac{\left[w_{1}+w_{i, 2}\right]}{\left(w_{1}\right)^{1 / 2} \cdot\left(w_{2}\right)^{1 / 2}}<\left(\frac{w_{2}}{w_{1}}\right)^{1 / 2} \Longleftrightarrow w_{2}>\frac{\psi}{2} w_{1},
$$

which is condition (12) from the main text. If this condition is fulfilled, the couple wishes a level of home consumption which can be produced with both spouses working less than their full time endowment in home production. Then, both spouses also participate in the labor market. If the condition is fulfilled, the efficient level of home consumption determines the two spouses' time inputs in home production:

$$
\begin{aligned}
h_{1} & =d \cdot\left(\frac{w_{1}}{w_{2}}\right)^{-1 / 2}=\frac{\psi}{2+\psi} \cdot \frac{\left[w_{1}+w_{2}\right]}{\left(w_{1}\right)^{1 / 2} \cdot\left(w_{2}\right)^{1 / 2}} \cdot\left(\frac{w_{1}}{w_{2}}\right)^{-1 / 2} \\
& =\frac{\psi}{2+\psi} \cdot \frac{w_{1}+w_{2}}{w_{1}} \\
h_{2} & =d \cdot\left(\frac{w_{1}}{w_{2}}\right)^{1 / 2}=\frac{\psi}{2+\psi} \cdot \frac{\left[w_{1}+w_{2}\right]}{\left(w_{1}\right)^{1 / 2} \cdot\left(w_{2}\right)^{1 / 2}} \cdot\left(\frac{w_{1}}{w_{2}}\right)^{1 / 2} \\
& =\frac{\psi}{2+\psi} \cdot \frac{w_{1}+w_{2}}{w_{2}}
\end{aligned}
$$

The remaining time is spent on market work:

$$
\begin{aligned}
& n_{1}=1-h_{1}=\frac{2}{2+\psi}-\frac{\psi}{2+\psi} \cdot \frac{w_{2}}{w_{1}} \\
& n_{2}=1-h_{2}=\frac{2}{2+\psi}-\frac{\psi}{2+\psi} \cdot \frac{w_{1}}{w_{2}}
\end{aligned}
$$


2. If the participation condition (12) is not fulfilled, (8) and (11) intersect in the second part of their piecewise definitions:

$$
2 w_{1} d=\psi \frac{w_{1} \cdot\left(1-d^{2}\right)}{d} \Longleftrightarrow d=\left(\frac{\psi}{2+\psi}\right)^{1 / 2}
$$

The time inputs in home production of the two spouses are

$$
\begin{aligned}
& h_{1}=d^{2}=\frac{\psi}{2+\psi} \\
& h_{2}=1 .
\end{aligned}
$$

Again, the remaining time is spent on paid market work:

$$
\begin{aligned}
& n_{1}=1-h_{1}=\frac{2}{2+\psi} \\
& n_{2}=1-h_{2}=0
\end{aligned}
$$

\section{D.2 Derivation of wives' hours by the husband's wage}

The integrals in equation (17) evaluate as follows, yielding equation (18):

$$
\begin{aligned}
n_{F}\left(w_{M}\right)= & (1-\xi) \cdot \int_{w_{\min }}^{\frac{\psi}{2} w_{M}} 0 \mathrm{~d} w_{F}+(1-\xi) \cdot \int_{\frac{\psi}{2} w_{M}}^{\frac{2}{\psi} w_{M}}\left[\frac{2}{2+\psi}-\frac{\psi}{2+\psi} \cdot \frac{w_{M}}{w_{F}}\right] \mathrm{d} w_{F} \\
& +(1-\xi) \cdot \int_{\frac{2}{\psi} w_{M}}^{w_{\min }+1} \frac{2}{2+\psi} \mathrm{d} w_{F}+\xi \cdot\left[\frac{2}{2+\psi}-\frac{\psi}{2+\psi} \cdot \frac{w_{M}}{w_{M}-\alpha}\right] \\
= & \frac{2}{2+\psi}+(1-\xi) \cdot \frac{2}{2+\psi} \cdot\left(w_{\min }-\frac{\psi}{2} w_{M}\right) \\
& -(1-\xi) \cdot \frac{\psi}{2+\psi} \cdot w_{M} \cdot \int_{\frac{\psi}{2} w_{M}}^{\frac{2}{\psi} w_{M}}\left[\frac{1}{w_{F}}\right] \mathrm{d} w_{F}-\xi \cdot \frac{\psi}{2+\psi} \cdot \frac{w_{M}}{w_{M}-\alpha} \\
= & \frac{2}{2+\psi}+(1-\xi) \cdot \frac{2}{2+\psi} \cdot\left(w_{\min }-\frac{\psi}{2} w_{M}\right) \\
& -(1-\xi) \cdot \frac{\psi}{2+\psi} \cdot w_{M} \cdot\left[\ln w_{F}\right]_{\frac{\psi}{2} w_{M}}^{\frac{2}{\psi} w_{M}}-\xi \cdot \frac{\psi}{2+\psi} \cdot \frac{w_{M}}{w_{M}-\alpha} \\
= & \frac{2}{2+\psi}+(1-\xi) \cdot \frac{2}{2+\psi} \cdot w_{\min }
\end{aligned}
$$




$$
-(1-\xi) \cdot \frac{\psi}{2+\psi} \cdot\left(1+\ln \frac{4}{\psi^{2}}\right) \cdot w_{M}-\xi \cdot \frac{\psi}{2+\psi} \cdot \frac{w_{M}}{w_{M}-\alpha}
$$

\section{D.3 Hump-shaped pattern of wives' hours by the husband's wage}

For $0<\xi<1$, the right hand side of equation (19) is a strictly concave function of $w_{M}$. Thus, when there is a local extremum, it is a maximum. In this appendix, we show that for any combination of $\psi, w_{\min }$, and $\alpha$, there is a $\xi$ such that $n_{F}\left(w_{M}\right)$ has a local extremum in the interior of the support of male wages. This is equivalent to the statement that, for all marginal distributions of wages, there is a degree of assortative mating such the pattern of wives' hours by the husband's wage is hump-shaped.

The first derivative of equation (19) is

$$
n_{F}^{\prime}\left(w_{M}\right)=-(1-\xi) \cdot \frac{\psi}{2+\psi} \cdot\left(1+\ln \frac{4}{\psi^{2}}\right)+\xi \cdot \frac{\psi}{2+\psi} \cdot \frac{\alpha}{\left(w_{M}-\alpha\right)^{2}}
$$

Since $n_{F}\left(w_{M}\right)$ is concave, it is sufficient to show that there is a $\xi^{*}$ such that $n_{F}^{\prime}\left(w_{M}\right)$ has a root on $\left(w_{\min }+\alpha, w_{\min }+\alpha+1\right)$. A root $w_{M}^{*}$ satisfies

$$
\begin{aligned}
\left(1-\xi^{*}\right) \cdot\left(1+\ln \frac{4}{\psi^{2}}\right) & =\xi^{*} \cdot \frac{\alpha}{\left(w_{M}^{*}-\alpha\right)^{2}} \\
& \Longleftrightarrow\left(w_{M}^{*}-\alpha\right)=\sqrt{\frac{\xi^{*}}{1-\xi^{*}}} \cdot \sqrt{\frac{\alpha}{1+\ln \frac{4}{\psi^{2}}}}
\end{aligned}
$$

The root lies in the support of the male wage distribution when

$$
w_{\min }<\sqrt{\frac{\xi^{*}}{1-\xi^{*}}} \cdot \sqrt{\frac{\alpha}{1+\ln \frac{4}{\psi^{2}}}}<w_{\min }+1 .
$$

Since $\sqrt{\frac{\alpha}{1+\ln \frac{4}{\psi^{2}}}}>0$ due to the restriction $\psi<2$ and

$$
\begin{aligned}
& \lim _{\xi \rightarrow 0} \sqrt{\frac{\xi}{1-\xi}}=0, \\
& \lim _{\xi \rightarrow 1} \sqrt{\frac{\xi}{1-\xi}}=\infty,
\end{aligned}
$$

there is always a $\xi^{*} \in(0,1)$ such that $(22)$ is fulfilled. 